\title{
The carbon-Ferrier rearrangement: an approach towards the synthesis of $C$-glycosides
}

\author{
Alafia Ali Ansari, Rima Lahiri, and Yashwant D. Vankar* \\ Department of Chemistry, Indian Institute of Technology Kanpur, Kanpur 208 016, India \\ E-mail:vankar@iitk.ac.in
}

This article is respectfully dedicated to Professor Dr. Richard R. Schmidt on the occasion of his $78^{\text {th }}$ birthday

\begin{abstract}
The carbon-Ferrier rearrangement is the reaction of appropriately functionalised glycals, with a variety of carbon nucleophiles such as allyltrimethylsilanes, alkynyltrimethylsilanes, silyl cyanides etc. involving the corresponding nucleophilic addition at the anomeric carbon with concomitant loss of a substituent at C-3. This leads to double bond migration to give 2,3unsaturated sugars which act as useful chiral substrates for further manipulations in organic synthesis.
\end{abstract}

Keywords: Ferrier rearrangement, C-glycosides, unsaturated carbohydrates, allyltrimethylsilanes, alkynylsilanes

\section{Table of Contents}

1. Introduction

2. Allylic Silanes as Nucleophiles

2.1 Allylsilanes

2.2 Substituted allylsilanes

3. Enol Silyl Ethers as Nucleophiles

4. Organometallic Nucleophiles

5. Propargyl or Alkynyl Silanes

6. Silyl Cyanides

7. Other Nucleophiles

7.1 Silyl ketene acetals

7.2 Aromatic nucleophiles

7.3 Electron-rich nucleophiles

7.4 Olefins 
7.5 Isocyanides

7.6 Allenyl silanes

7.7 Organoboron compounds

8. Conclusions

9. Acknowledgements

References

\section{Introduction}

The well-known Ferrier rearrangement ${ }^{1}$ involves the reaction of a suitably protected 1,2-glycal with an alcohol under Lewis acid catalysis to form the corresponding 2,3-unsaturated 1-Oglycosides. Such 1-O-glycosides have been transformed into a variety of useful intermediates both in organic synthesis as well as specifically in carbohydrate chemistry. Likewise, there have been reports on aza- $^{1 \mathrm{~h}}$ and thia- ${ }^{1 \mathrm{i}}$ Ferrier rearrangements. Several papers and reviews on this and allied topics have appeared in the literature. ${ }^{1}$

Since $C$-glycosides are stable analogs of $O$-glycosides and less prone to cleavage at the anomeric carbon, they have gained considerable importance in the last few decades. Among several approaches towards $C$-glycosides, the Ferrier rearrangement utilising C-nucleophiles has been found to be quite useful. Several catalysts and nucleophiles have been introduced in the literature addressing $\alpha / \beta$-selectivity, mildness of the method, effect of solvent, effect of acid (or Lewis acid) catalyst, and yields of the products. In this review, a brief account of several methods that have been reported in the literature since 1982 is presented.

\section{Allylic Silanes as Nucleophiles}

\subsection{Allyl silanes}

Amongst the carbon nucleophiles used for $C$-Ferrier reactions, allyltrimethylsilanes (ATMS) have been most prominent. The first examples of such reactions were reported by Danishefsky et $a l^{2}{ }^{2}$ where glycal acetates 1-4 (Table 1) were observed to undergo nucleophilic displacement and double bond migration in the presence of equimolar amounts of $\mathrm{TiCl}_{4}$ as a Lewis acid. The reactions were highly regioselective with allyl group addition at $\mathrm{C}_{1}$ position and shifting of double bond to $\mathrm{C}_{2}-\mathrm{C}_{3}$. The reaction proceeds with preference towards attack from the $\alpha$-side but the selectivity varied depending upon the stereochemistry of other groups on the pyranose ring. 
Table 1. Reaction of glycals with 1 eq. $\mathrm{TiCl}_{4}$ and 1.5 eq. ATMS at $-78{ }^{\circ} \mathrm{C}$

\begin{tabular}{|c|c|c|}
\hline Glycals & Yield & $\alpha: \beta$ \\
\hline & $85 \%$ & $16: 1$ \\
\hline & $95 \%$ & $6: 1$ \\
\hline & $93 \%$ & $30: 1$ \\
\hline & $95 \%$ & $1: 0$ \\
\hline
\end{tabular}

Stereoselective allylation at the $\mathrm{C}_{1}$ position in 1-alkylglucal 5 was reported by Nicolaou and group using $\mathrm{TiCl}_{4}$ (Scheme 1). ${ }^{3}$ The nucleophile attacks from the $\alpha$-face of the molecule as the oxonium ion intermediate would preferentially convert into the energetically favoured half chair conformer 7 (Figure 1).

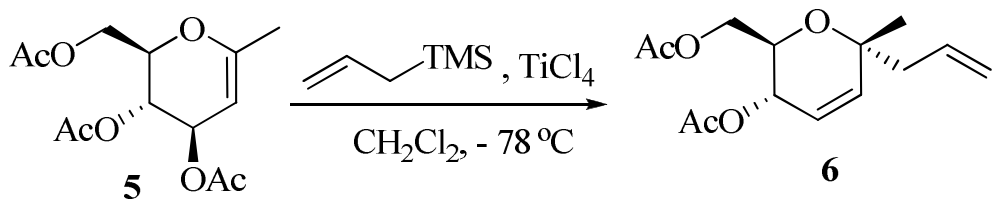

\section{Scheme 1}

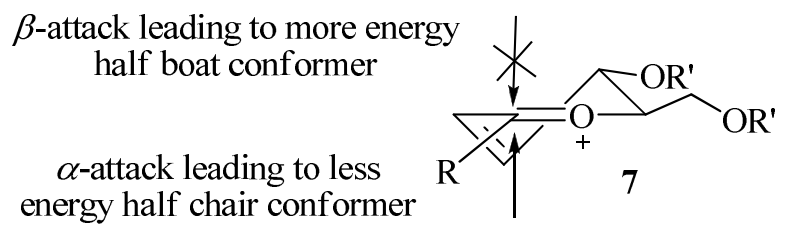

Figure 1. Proposed explanation to $\alpha$-selectivity of allyl addition.

Isobe et $\mathrm{al}^{4}$ reported the use of $\mathrm{BF}_{3} . \mathrm{OEt}_{2}$ as a catalyst for the generation of the $\alpha$ - and $\beta$-anomers 8 from acetylated glucal 1 in 94:6 ratio, which were separated by column chromatography with great difficulty (Scheme 2). 

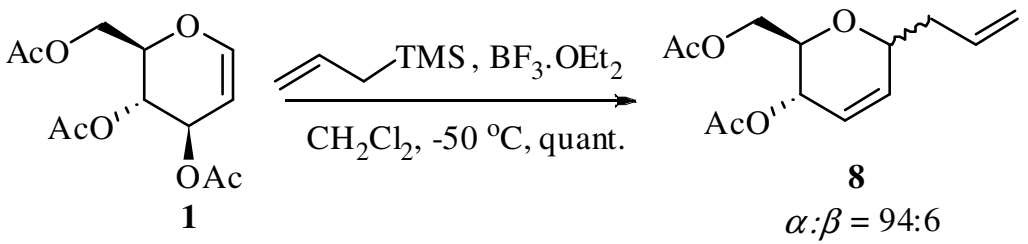

\section{Scheme 2}

The first aza-Ferrier reaction on $N$-carbethoxytetrahydropyridine derivative 9 with two equivalents of allyltrimethylsilane was reported by Kozikowski et al. ${ }^{5}$ (Scheme 3). While excellent yields of the product $\mathbf{1 0}$ were observed in the presence of $\mathrm{SnCl}_{4}(90 \%)$ and $\mathrm{TiCl}_{4}$ $(89 \%), \mathrm{BF}_{3} . \mathrm{OEt}_{2}$ and TMSOTf produced the desired compound in moderate yields of $43 \%$ and $51 \%$, respectively.

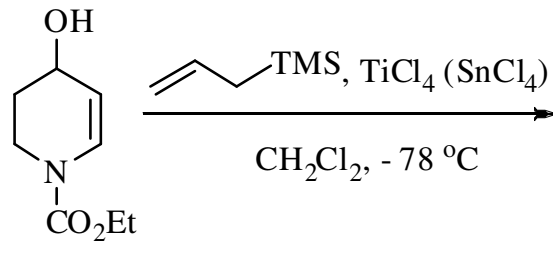

9<smiles>C=CCC1C=CCCN1C(=O)OCC</smiles>

10

\section{Scheme 3}

Toshima and co-workers ${ }^{6}$ reported highly stereoselective formation of allyl- $\alpha$ - $C$-glycosides when glycal acetates such as 1, 3, 11-13 were treated with allyltrimethylsilane in the presence of $30-50$ mol\% of 2,3-dichloro-5,6-dicyano- $p$-benzoquinone (DDQ) as a neutral activator (Table 2). Increase or decrease in the amount of activator caused lowering of product yield. Use of allyltributyltin under similar conditions yielded the product in $58 \%$ yield.

Table 2. Reactivity and selectivity in various glycals with allyltrimethylsilane and DDQ<smiles></smiles>

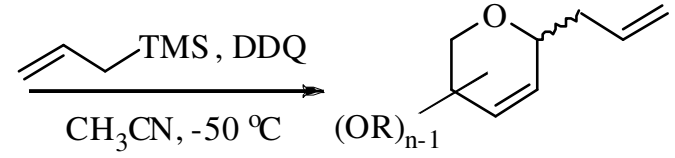

\begin{tabular}{ccccc}
\hline Glycals & $\mathrm{T}\left({ }^{\circ} \mathrm{C}\right)$ & Time $(\mathrm{h})$ & Yield $(\%)$ & $\alpha: \beta$ \\
\hline & 50 & 12 & 90 & $15: 1$ \\
\hline
\end{tabular}


Table 2. Continued

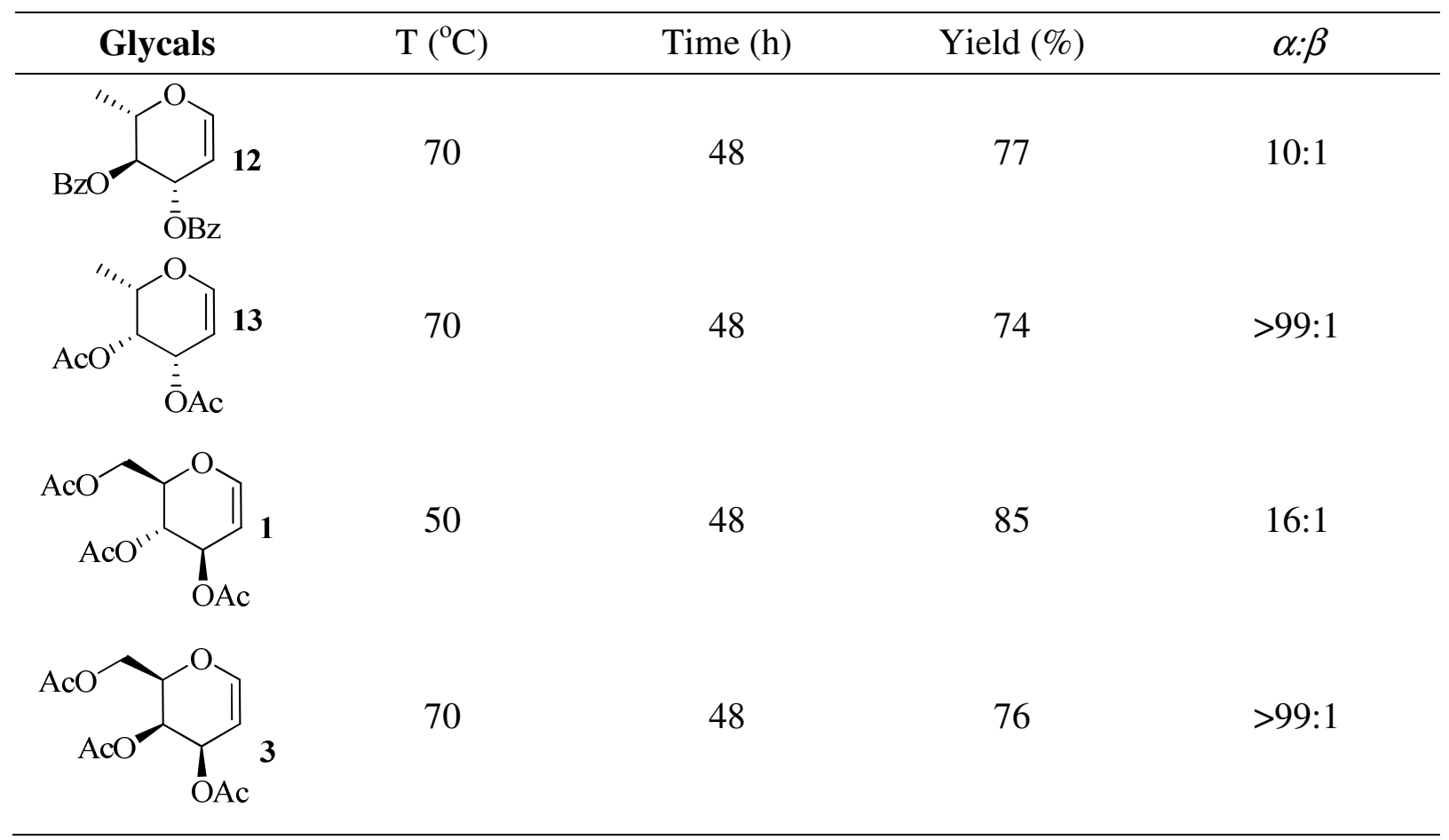

From the same group, 10 mass \% of Montmorillonite K-10 was found to be a suitable catalyst for effecting Ferrier rearrangement in acetylated glycals using allyltrimethylsilane as the source of nucleophile (Scheme 4). The reaction followed good $\alpha$-selectivity irrespective of the stereochemical disposition of the groups on the glycal. ${ }^{7}$

\section{Scheme 4}

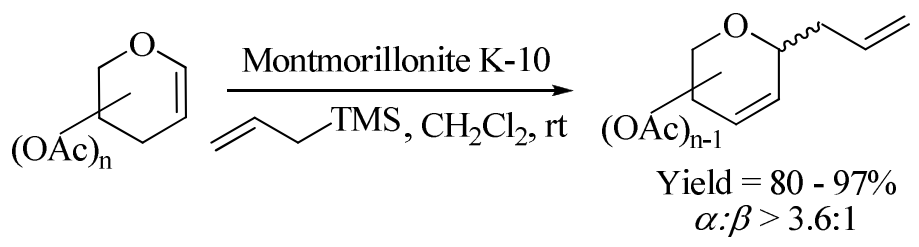

Also, stereoselective allyl $\alpha$-C-glycosidation using unprotected glycals 14-17 (Table 3) was successfully achieved in the presence of equimolar amounts of TMSOTf at low temperatures by the same group. ${ }^{8}$ Selective formation of $C$-glycosides was promoted by low temperature conditions $\left(-78^{\circ} \mathrm{C}\right)$. The yield of the reactions was observed to be dependent on the solvent.

Studies on pentapyranose derivatives 18 and 19 by Isobe and co-workers ${ }^{9}$ revealed 1,4-anti diastereoselectivity (>95:5) in the addition of allyl nucleophile, giving 20 and $\mathbf{2 1}$ in the presence of $\mathrm{BF}_{3} . \mathrm{OEt}_{2}$ (Scheme 5). This observation is in contrast to the reactions of hexapyranoses which exhibit 1,5-anti diastereoselectivity. The authors have rationalised this difference by the conformations of the oxonium ion intermediates. While for the hexapyranoses the stereochemistry is guided by the equatorial orientation of the C-5 substituent, the pentapyranoses 
favour the transition state having quasi-axial orientation of the $\mathrm{C}-4$ substituent which is 1.5 $\mathrm{kcal} / \mathrm{mol}$ more stable than the quasi-equatorial conformer.

Table 3. Reaction of unprotected glycals with TMSOTf

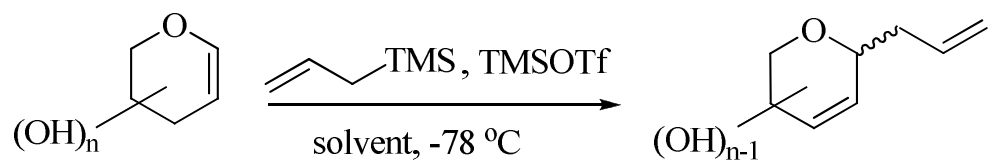

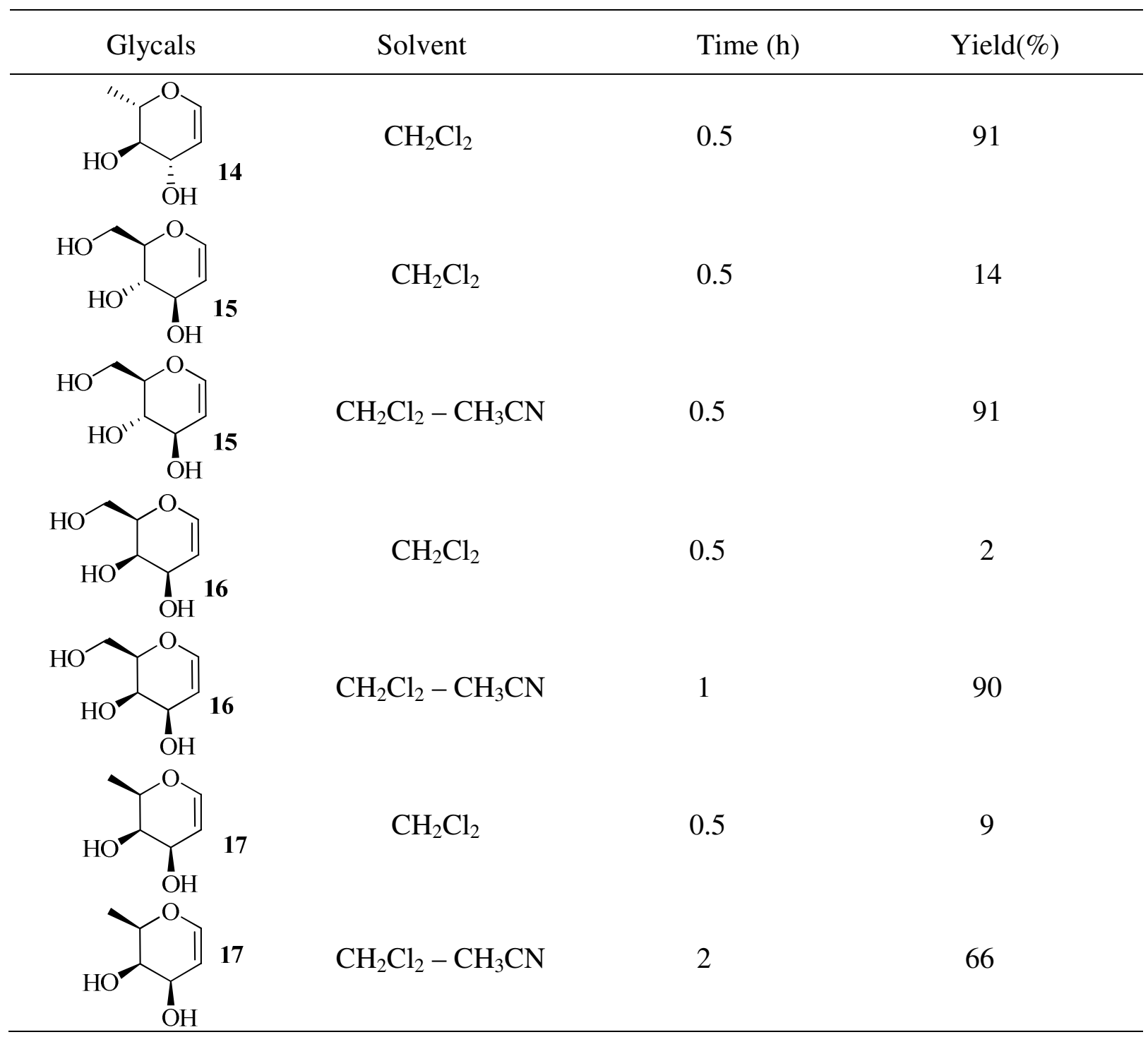


<smiles>[R]C1([R2])COC=C[C@@H]1OC(C)=O</smiles>

18: $\mathrm{R}^{1}=\mathrm{OAc}, \mathrm{R}^{2}=\mathrm{H}$

19: $\mathrm{R}^{1}=\mathrm{H}, \mathrm{R}^{2}=\mathrm{OAc}$

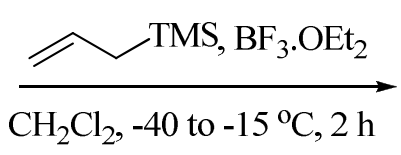

20: $\mathrm{R}^{1}=\mathrm{OAc}, \mathrm{R}^{2}=\mathrm{H} ; 99 \%, \alpha: \beta=5: 95$

21: $\mathrm{R}^{1}=\mathrm{H}, \mathrm{R}^{2}=$ OAc; $95 \%, \alpha: \beta=95: 5$

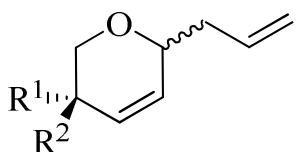

$\mathrm{R}^{2}$

\section{Scheme 5}

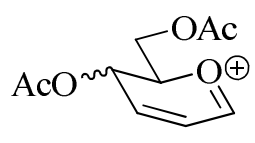

Favoured T.S. for hexapyranoses

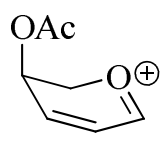

Favoured T.S. for pentopyranoses 


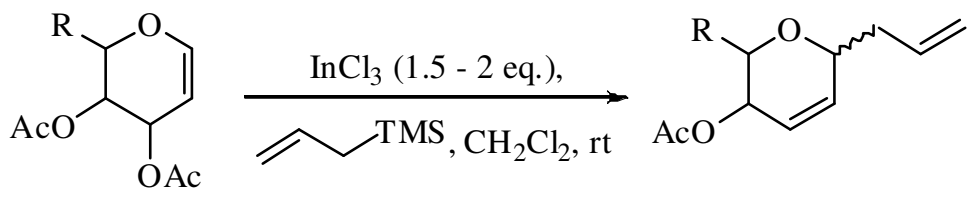

$$
\mathrm{R}=\mathrm{H}, \mathrm{Me}, \mathrm{CH}_{2} \mathrm{OAc}
$$

Yield $=70-100 \%$ $\alpha: \beta>9: 1$<smiles>[R]C1OC=CC(OC(C)=O)C1OC(C)=O</smiles>

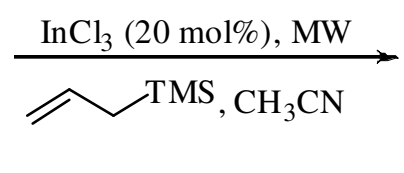<smiles>[R]C1O[C@@H](CC=C)C=CC1O[C@@H](C)O</smiles>

$$
\mathrm{R}=\mathrm{H}, \mathrm{Me}, \mathrm{CH}_{2} \mathrm{OAc}
$$

$$
\begin{gathered}
\text { Yield }=85-95 \% \\
\alpha: \beta>13: 1
\end{gathered}
$$<smiles>[R]C1C=COC([R])C1[R]</smiles>

$\mathrm{R}_{1}=\mathrm{H}, \mathrm{Me}, \mathrm{CH}_{2} \mathrm{OAc}, \mathrm{OBn}, \mathrm{OBz}$

$\mathrm{R}_{2}=\mathrm{CH}_{2} \mathrm{OAc}, \mathrm{OBn}, \mathrm{OBz}$

$\mathrm{R}_{3}=\mathrm{CH}_{2} \mathrm{OAc}, \mathrm{OBn}, \mathrm{OBz}$<smiles>[R]C1C=C[C@@H](CC=C)OC1[R]</smiles>

Yield $=87-95 \%$

$\alpha: \beta>7: 1$

\section{Scheme 6}

Table 4. Lewis acids used for carbon-Ferrier reactions with ATMS as nucleophile

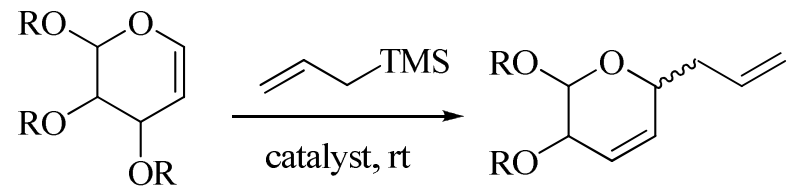

$\mathrm{R}=\mathrm{Ac}, \mathrm{Bz}$, Piv

\begin{tabular}{ccccc}
\hline Catalyst & Solvent & Yield(\%) & $\alpha: \beta$ & Ref. \\
\hline $\mathrm{Sc}(\mathrm{OTf})_{3}$ & $\mathrm{CH}_{2} \mathrm{Cl}_{2}$ & $84-93$ & $9: 1$ & $11 \mathrm{a}$ \\
$\mathrm{I}_{2}$ & $\mathrm{CH}_{2} \mathrm{Cl}_{2}$ & $84-95$ & $>8: 2$ & $11 \mathrm{~b}$ \\
$\mathrm{InBr}_{3}$ & $\mathrm{CH}_{2} \mathrm{Cl}_{2}$ & $88-93$ & $9: 1$ & $11 \mathrm{c}$ \\
$\mathrm{Bi}(\mathrm{OTf})_{3}$ & $\mathrm{CH}_{3} \mathrm{CN}$ & $88-95$ & $>9: 1$ & $11 \mathrm{~d}$ \\
$\mathrm{PMA}_{3} \mathrm{SiO}_{2}$ & $\mathrm{CH}_{3} \mathrm{CN}$ & $85-90$ & Only $\alpha$ & $11 \mathrm{e}$ \\
\hline
\end{tabular}

As reported by Schmidt et al., ${ }^{12 a}$ reaction of per- $O$-acetylated glycals with allyltrimethylsilane and (2-bromoallyl)trimethylsilane in the presence of $10 \mathrm{~mol} \%$ of $\mathrm{Yb}(\mathrm{OTf})_{3}$ was observed to generate the corresponding $\alpha$-glycosides $\mathbf{8}$ and $\mathbf{2 2}$ stereospecifically in excellent yields. This method, as shown in Scheme 7, has been utilised later by Sasaki et al. for the synthesis of neodysiherbaine. ${ }^{12 \mathrm{~b}}$ Subsequently, Gree et al. reported that glycals react smoothly with allyltrimethylsilanes under $\mathrm{Yb}(\mathrm{OTf})_{3}$ catalysis when used in $[\mathrm{bmim}]\left[\mathrm{BF}_{4}\right]$ as ionic liquid, 
resulting in the corresponding $C$-glycosides $\mathbf{8}$ or $\mathbf{2 3}$ in $80 \%$ yield. The reaction was observed to be highly stereoselective with preference towards the $\alpha$-anomer. ${ }^{12 \mathrm{c}}$<smiles>CC(=O)OC[C@H]1OC=C[C@@H](OC(C)=O)[C@H]1OC(C)=O</smiles>

1<smiles>CC(=O)OC[C@H]1OC=C[C@@H](OC(C)=O)[C@H]1OC(C)=O</smiles>

1
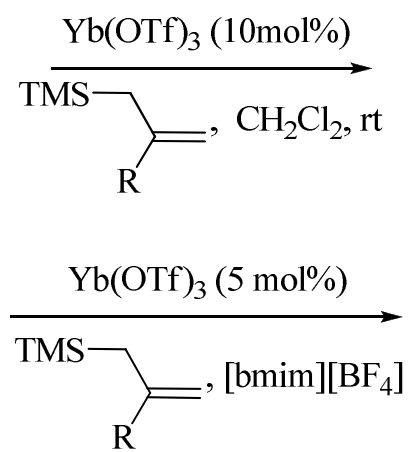

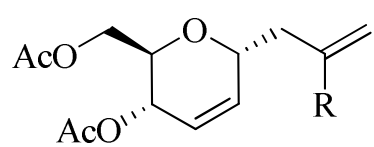

8: $\mathrm{R}=\mathrm{H}$, Yield $=94 \%$

22: $\mathrm{R}=\mathrm{Br}$, Yield $=89 \%$<smiles></smiles>

8: $\mathrm{R}=\mathrm{H}$, Yield $=80 \%$

23: $\mathrm{R}=$ Me, Yield $=80 \%$

\section{Scheme 7}

Venkateswarlu et al. ${ }^{13}$ have reportedly used $5 \mathrm{~mol} \%$ of $\mathrm{ZrCl}_{4}$ as catalyst for Ferrier reaction on acetylated glycals with allyltrimethylsilane as nucleophile producing the expected products in excellent yields with very good selectivity (Scheme 8).

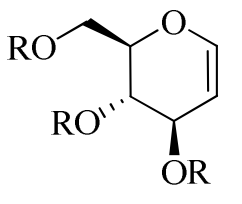

$\mathrm{R}=\mathrm{Ac}, \mathrm{Bz}, \mathrm{Bn}$

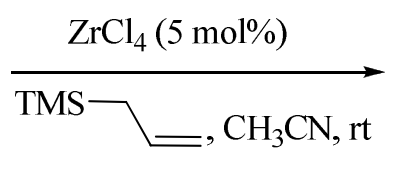

\section{Scheme 8}

Misra and co-workers ${ }^{14}$ have reported $\mathrm{HClO}_{4}-\mathrm{SiO}_{2}$ as an insoluble catalyst promoting the Ferrier rearrangement on glycals. $50 \mathrm{mg}$ of the solid supported catalyst was found to be effective for $1 \mathrm{mmol}$ of the glycal, rapidly generating the desired products in $75-85 \%$ yields with excellent selectivity as shown in Scheme 9.

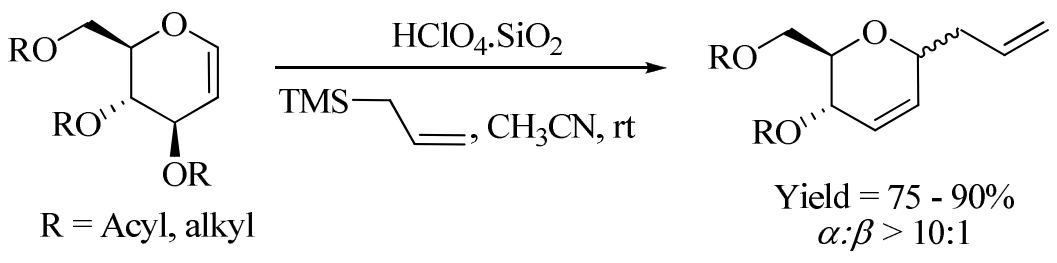

\section{Scheme 9}

Lin and coworkers ${ }^{15 a}$ reported the reaction of exo- and endo-glycals with allyltrimethylsilane in the presence of 10 equivalents of trifluoroacetic acid (TFA) yielding the desired products in about 85\%, with selectivity towards the $\alpha$-anomer 25 and 27 (Scheme 10). The same 
reagent was used by Gallagher et al. ${ }^{15 b}$ in the synthesis of a novel laulimalide analogue via intermediate $\mathbf{8}$.<smiles>CC(=O)OC/C=C1/O[C@H](COCc2ccccc2)[C@@H](Br)[C@H](O)[C@H]1Cc1ccccc1</smiles>

24<smiles>OC[C@H]1C=CO[C@@H](COc2ccccc2)[C@@H]1Br</smiles>

26: $\mathrm{R}=\mathrm{CO}^{t} \mathrm{Bu}, \mathrm{Bn}$

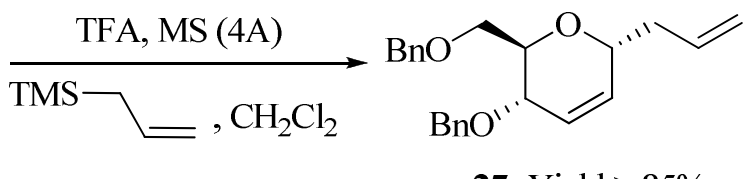

27: Yield $>85 \%$<smiles>CC(=O)OC[C@H]1OC=C[C@H](OC(C)=O)[C@H]1OC(C)=O</smiles>

1

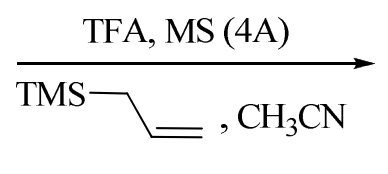

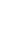

\section{Scheme 10}

Erbium(III) triflate when used in 3 mol\% with allyltrimethylsilane produced $C$-pseudoglycosides from acetylated glycals (Scheme 11). ${ }^{16}$ The corresponding $\alpha$-glycosides were obtained in good yields.
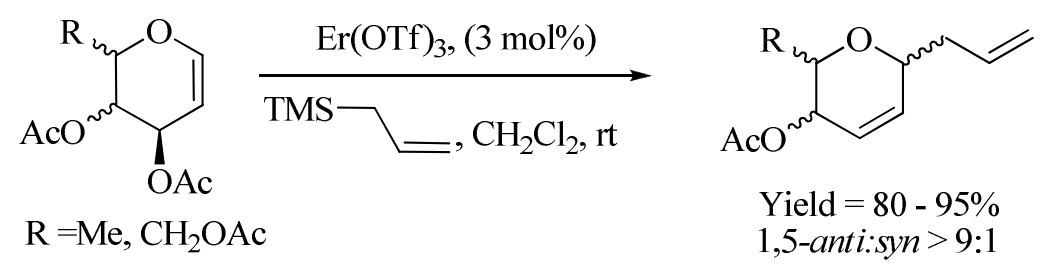

\section{Scheme 11}

Phenylsulfonylethylidene (PSE) protected glycals 28 were observed to undergo the Ferrier reaction with allyltrimethylsilane on being activated by TMSOTf to give product $\mathbf{2 9}$ as shown in Scheme $12 .^{17}$<smiles>CC(=O)O[C@H]1C=CO[C@@H]2COC(CO[SbH])O[C@H]12</smiles>

28

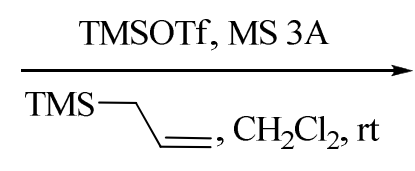

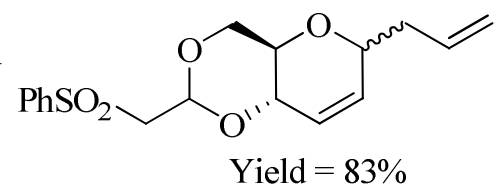

29

\section{Scheme 12}


A catalytic amount of $\mathrm{AuCl}_{3}$ was also found to be efficient in promoting $C$-allyl product formation. ${ }^{18}$ The reaction produced the expected compounds in good yields with the $\alpha$-isomer predominating (Scheme 13).

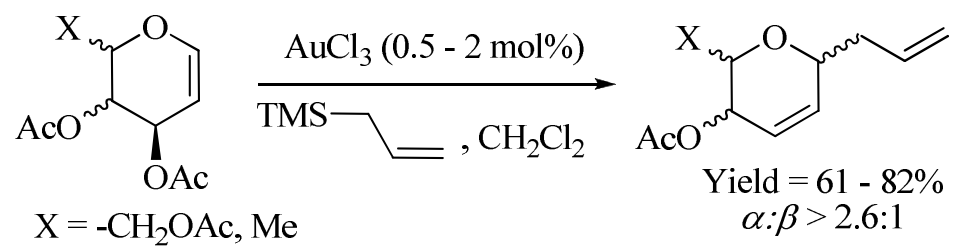

\section{Scheme 13}

Ultrastable Y-zeolites have been reported by Gammon et al. ${ }^{19}$ to catalyze $C$-allylation on acetylated glycal with formation of the corresponding $\alpha$-anomer selectively (Scheme 14).

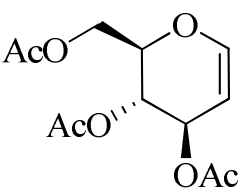

1

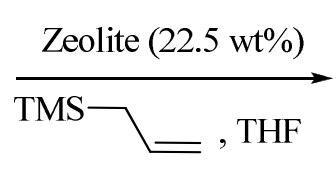

\section{Scheme 14}

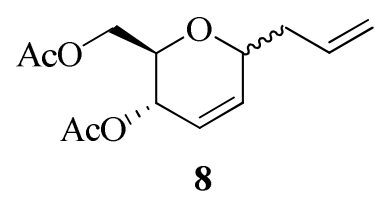

Yield $=70 \%$

$\alpha: \beta>2: 1$

\subsection{Substituted allylsilanes as nucleophiles}

Danishefsky et al. ${ }^{20}$ explored the selectivity of nucleophilic attack of $(E)$ - and (Z)- crotylsilanes 30 on substituted glycals. The rearrangement was promoted by $\mathrm{BF}_{3} \cdot \mathrm{OEt}_{2}$ to give the $\alpha$-configurated pseudoglycosides. Several glycal-like substrates were treated by the silanes. While the $E$-silane yielded predominantly $\mathrm{C}_{1}$-anti product, the $Z$-silane gave the $\mathrm{C}_{1}$-syn isomer as the major products. On incorporating a substituent at C-2 position or an electron withdrawing group at C-3 position, the anti:syn ratio increased considerably. These observations are summarised in Scheme 15.

Subsequently, Panek et al. $^{21}$ reported the Lewis acid mediated attack of substituted crotylsilanes $\mathbf{3 1}$ and $\mathbf{3 4}$ on glycal 1 as shown in Scheme 16. In their work, $\mathrm{BF}_{3} . \mathrm{OEt}_{2}$ was found to be most effective as a Lewis acid in contrast to TMSOTf and $\mathrm{TiCl}_{4}$. Upon treatment of triacetylated glucal 1 with $(R)$-silane 31, the isomer $\mathbf{3 3}$ was obtained as the major product while the $(S)$-silane $\mathbf{3 2}$ produced $\mathbf{3 4}$ as the major isomer. 

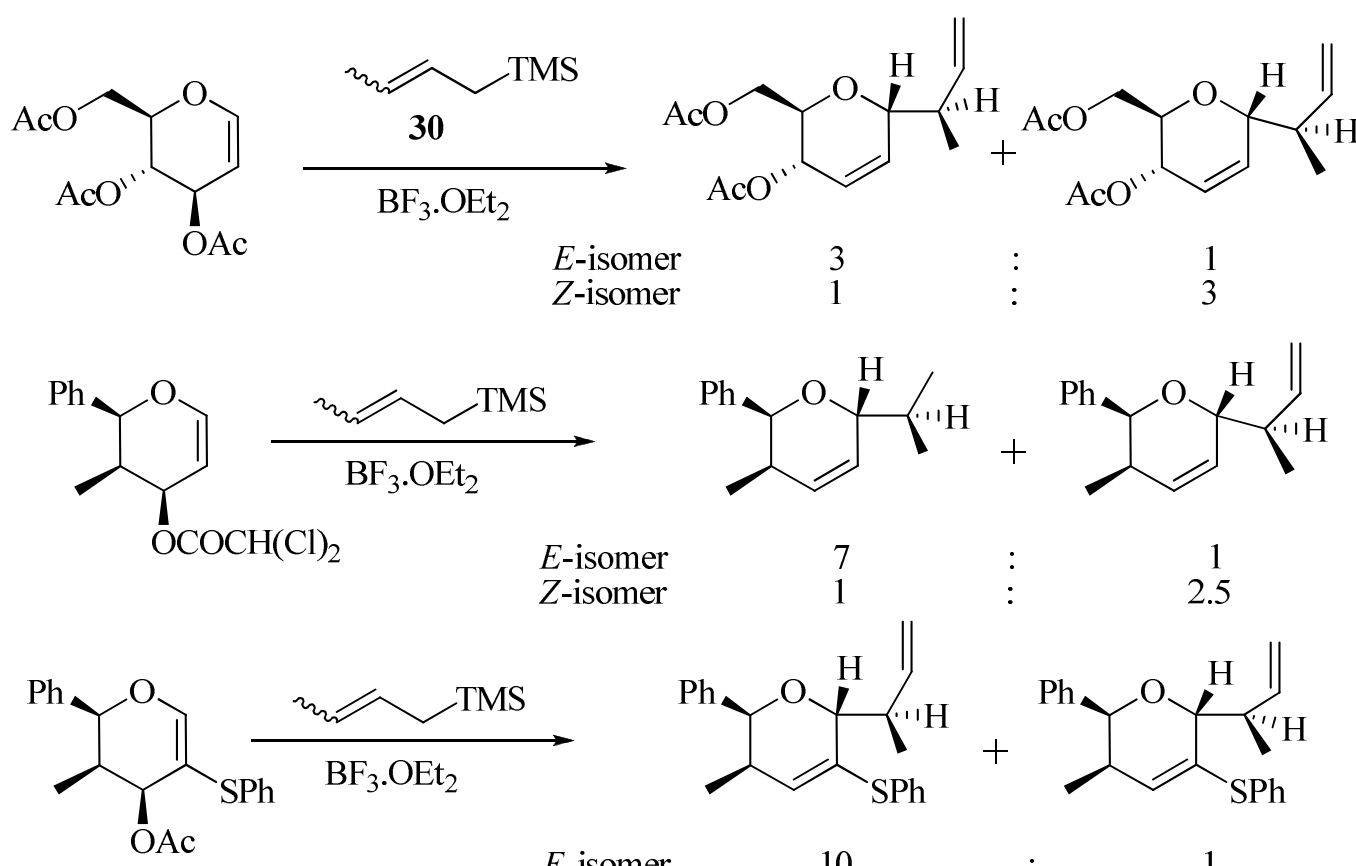

E-isomer

$Z$-isomer
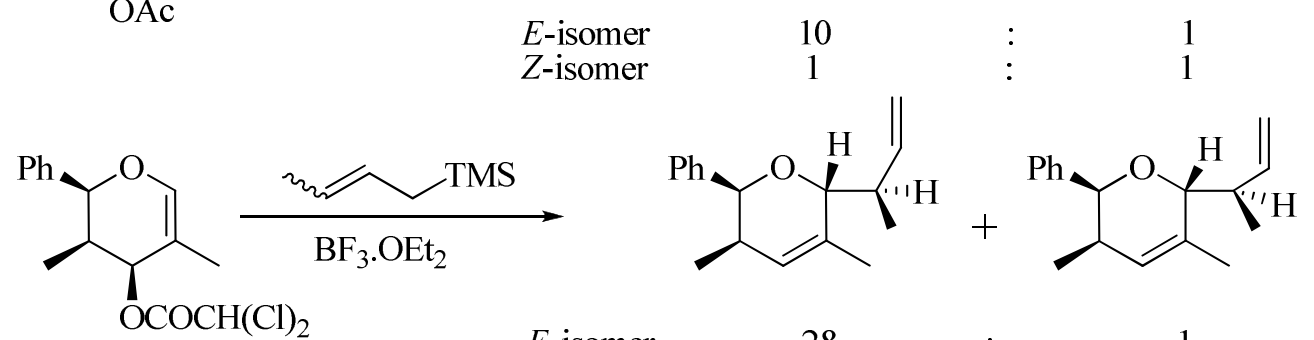

$\begin{array}{lccc}E \text {-isomer } & 28 & \vdots & 1 \\ Z \text {-isomer } & 2 & : & 1\end{array}$

\section{Scheme 15}

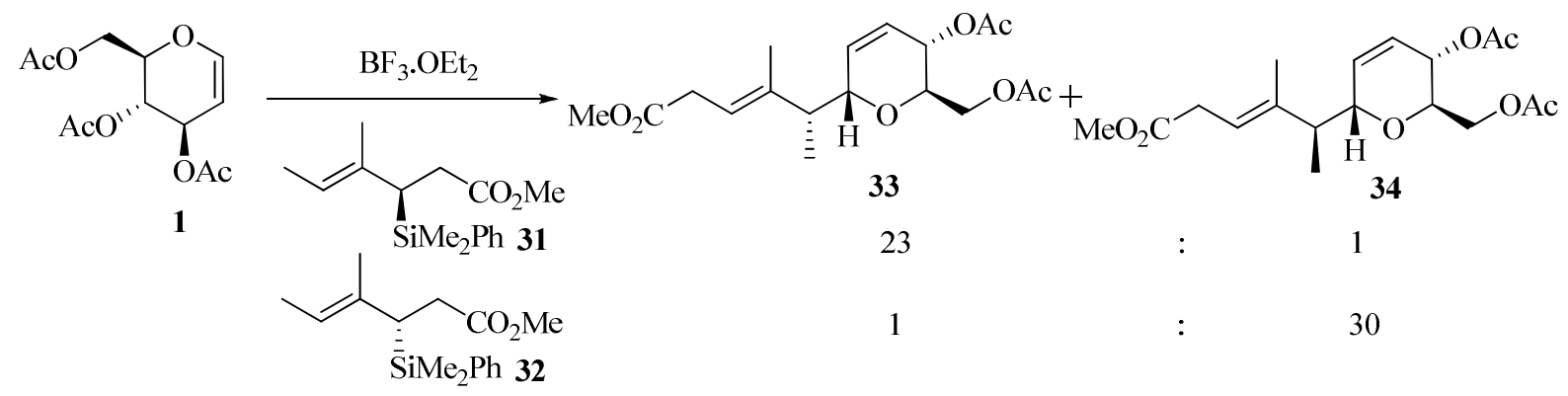

\section{Scheme 16}

\section{Enol Silyl Ethers as Nucleophiles}

Reaction of 1-(trimethylsilyloxy)styrene with tri- $O$-acetyl glucal 1 was first reportedly observed by Dawe and Fraser-Reid. ${ }^{22}$ The reaction proceeded in presence of 1.4 equivalents of $\mathrm{BF}_{3}$. $\mathrm{OEt}_{2}$ 
at $-40{ }^{\circ} \mathrm{C}$ producing the $C$-pseudoglycoside 35 in $99 \%$ yield with $\alpha$-anomeric selectivity (Table 5). Although the authors expected an increment in the ratio of selectivity in acetonitrile as solvent due to formation of nitrilium ion that would adopt a $\beta$-orientation, changing the solvent from dichloromethane to acetonitrile failed to provide any improvement.

Table 5. Silyl enol ether as nucleophile on acetylated glucal

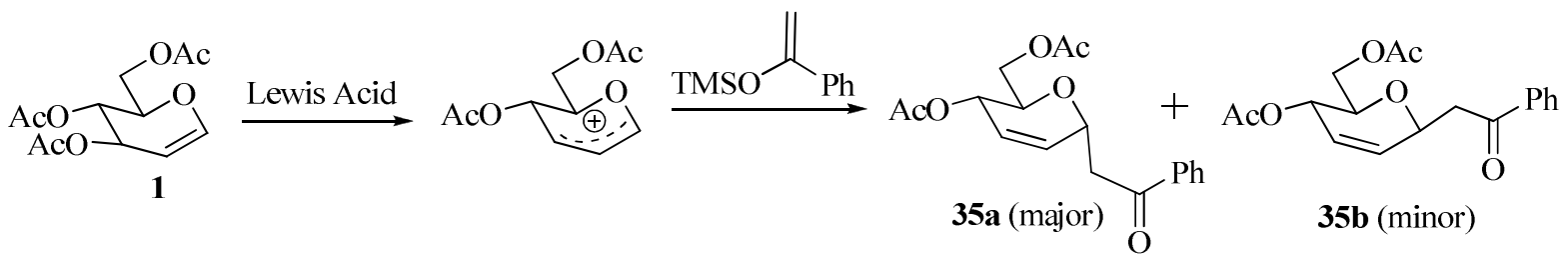

\begin{tabular}{cccccc}
\hline Catalyst & Solvent & Temp $\left({ }^{\circ} \mathrm{C}\right)$ & Time $(\mathrm{h})$ & Yield $(\%)$ & $\alpha: \beta$ \\
\hline $\mathrm{BF}_{3} \cdot \mathrm{OEt}_{2}$ & $\mathrm{CH}_{2} \mathrm{Cl}_{2}$ & $-40-0$ & 0.5 & 99 & $4: 1$ \\
$\mathrm{AlCl}_{3}$ & $\mathrm{THF}$ & 23 & 36 & 77 & $7: 3$ \\
$\mathrm{AlCl}_{3}$ & $\mathrm{CH}_{3} \mathrm{CN}$ & $-45-0$ & 1 & 97 & $4: 1$ \\
\hline
\end{tabular}

An Aza-Ferrier reaction on the $N$-carbethoxytetrahydropyridine derivative 9 with two equivalents of silyl enol ether in presence of 1.5 equivalents of TMSOTf to give the 1-acetyl-2oxopropyl derivative 36 in $84 \%$ yield has been reported by Kozikowski and Park, ${ }^{5}$ as shown in Scheme 17.<smiles>CCOC(=O)N1C=CC(O)CC1</smiles>

9

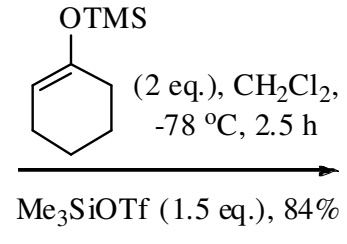<smiles>O=C1CCCCC1C1C=CCCN1C(=O)O</smiles>

36

\section{Scheme 17}

Lithium perchlorate has been identified as an effective promoter for the Ferrier reaction on acetylated glucal with silyl enol ether (ketene acetal) by Pearson and Schkeryantz. ${ }^{23}$ The $\alpha$ anomer of the ester $\mathbf{3 7}$ so formed was observed to be the major product (Scheme 18).

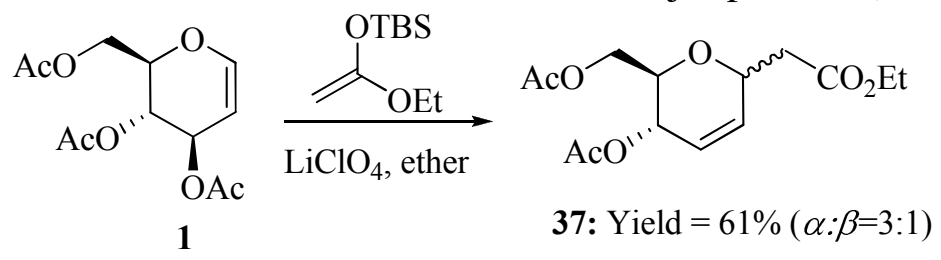

\section{Scheme 18}


Isobe et al. ${ }^{9}$ have reported the reaction of enol silyl ether on acetylated xylal $\mathbf{1 8}$ in presence of $\mathrm{BF}_{3} . \mathrm{OEt}_{2}$ to form the $\mathrm{C}-\mathrm{C}$ coupling product 38 in $65 \%$ yield. The reaction was observed to follow 1,4-anti selectivity in the ratio of 85:15 as shown in Scheme 19.<smiles>CC(=O)O[C@H]1C=COC[C@H]1OC(C)=O</smiles>

18

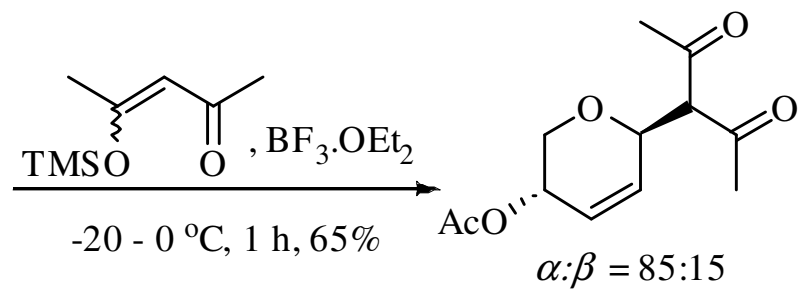

38

\section{Scheme 19}

$\mathrm{Yb}(\mathrm{OTf})_{3}$ has been found to be a good catalyst for reaction of several enol silyl ethers on acetylated glucal by Schmidt et al. ${ }^{12 \mathrm{a}}$ The reaction proceeded with good selectivity and excellent yields. Subsequently, Grée et al. ${ }^{12 \mathrm{c}}$ have reported the utilisation of $\mathrm{Yb}(\mathrm{OTf})_{3}$ in ionic liquid in the reaction of similar silyl enol ethers with glucal forming the desired products in moderate yields and good diastereoselectivity. These observations are summarized in Table 6.

Table 6. Ferrier rearrangement with enol silanes using catalytic $\mathrm{Yb}(\mathrm{OTf})_{3}$

\begin{tabular}{|c|c|c|c|c|c|c|c|}
\hline \multirow{2}{*}{ Acceptor } & \multirow{2}{*}{ Product } & \multicolumn{3}{|c|}{$10 \mathrm{~mol} \% \mathrm{Yb}(\mathrm{OTf})_{3}$} & \multicolumn{3}{|c|}{$\begin{array}{c}5 \mathrm{~mol} \% \mathrm{Yb}(\mathrm{OTf})_{3} \\
\text { in }[\mathrm{bmim}]\left[\mathrm{NTf}_{2}\right]\end{array}$} \\
\hline & & $\begin{array}{l}\text { Time } \\
\text { (h) }\end{array}$ & $\begin{array}{l}\text { Yield } \\
(\%)\end{array}$ & $\alpha: \beta$ & $\begin{array}{l}\text { Time } \\
(\mathrm{h})\end{array}$ & $\begin{array}{l}\text { Yield } \\
(\%)\end{array}$ & $\alpha: \beta$ \\
\hline & & 10 & 90 & $8: 1$ & 0.5 & 65 & $>95: 5$ \\
\hline & & 12 & 89 & 11:1 & 0.5 & 60 & $>95: 5$ \\
\hline & & 15 & 84 & $8: 1$ & - & - & - \\
\hline & & 12 & 88 & $5: 1$ & - & - & - \\
\hline
\end{tabular}


Table 6. Continue

\begin{tabular}{|c|c|c|c|c|c|c|c|}
\hline \multirow[b]{2}{*}{ Acceptor } & \multirow[b]{2}{*}{ Product } & \multicolumn{3}{|c|}{$10 \mathrm{~mol} \% \mathrm{Yb}(\mathrm{OTf})_{3}$} & \multicolumn{3}{|c|}{$\begin{array}{c}5 \mathrm{~mol} \% \mathrm{Yb}(\mathrm{OTf})_{3} \\
\text { in }[\mathrm{bmim}]\left[\mathrm{NTf}_{2}\right]\end{array}$} \\
\hline & & $\begin{array}{l}\text { Time } \\
\text { (h) }\end{array}$ & $\begin{array}{c}\text { Yield } \\
(\%)\end{array}$ & $\alpha: \beta$ & $\begin{array}{l}\text { Time } \\
\text { (h) }\end{array}$ & $\begin{array}{c}\text { Yield } \\
(\%)\end{array}$ & $\alpha: \beta$ \\
\hline & & & - & - & 0.5 & 40 & $>95: 5$ \\
\hline OTMS & & - & - & - & 1.5 & 60 & $>95: 5$ \\
\hline
\end{tabular}

Exo-Ferrier reaction on 39 with a silyl enol ether in the presence of trifluoroacetic acid, resulting in the formation of compound 40, containing a quaternary anomeric carbon, in $65 \%$ yield, has been reported by Lin and co-workers (Scheme 20). ${ }^{15 a}$<smiles>CCOCC=C1O[C@H](COCc2ccccc2)[C@@H](OCc2ccccc2)[C@H](CBr)[C@@H]1Cc1ccccc1</smiles>

39

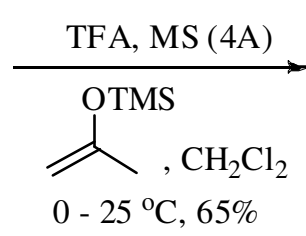

$0-25{ }^{\circ} \mathrm{C}, 65 \%$<smiles>CC(=O)C[C@]1(CCOC(C)=O)O[C@H](COCc2ccccc2)[C@@H](OCc2ccccc2)[C@H](Br)[C@@H]1OCc1ccccc1</smiles>

40: Y ield $=85 \%$

\section{Scheme 20}

\section{Organometallic Nucleophiles}

In 1986, Nicolaou and his group ${ }^{3}$ reported trialkylaluminium and alkylaluminium chloride as sources of the carbon nucleophile in Ferrier rearrangements of the triacetylated 1-methyl glucal 5 (Table 7). The reaction was promoted by $\mathrm{TiCl}_{4}$ and successfully yielded 1,1-dialkylated pseudoglycals $\mathbf{6}$ and 7 stereospecifically. The reaction proceeded via the transition state as described in Figure 1.

Orsini and Pelizzoni ${ }^{24}$ reportedly used the Reformatsky reagent tert-butoxycarbonylmethylzinc bromide $\mathbf{4 1}$ on acetylated glycals to bring about formation of pseudoglycosides in the presence of TMSOTf at $0{ }^{\circ} \mathrm{C}$. While the D-glucose derived olefin produced the $\alpha$-anomer as the major product, the selectivity was reversed in the D-galactose and L-rhamnose derived olefins $\mathbf{1 1}$ as shown in Table 8. The reactions produced the desired products in poor to moderate yields only. 
Table 7. Aluminium alkyls as carbon nucleophiles

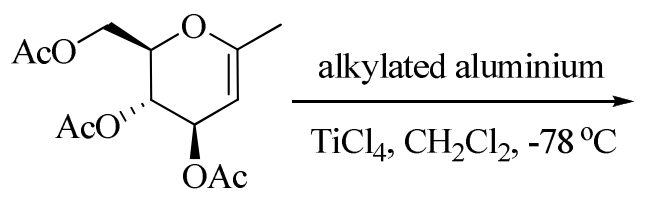

5

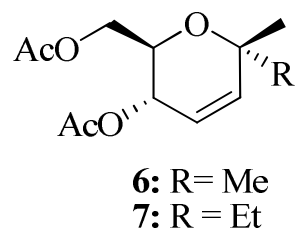

\begin{tabular}{ccc}
\hline Reagent & R & Yield (\%) \\
\hline $\mathrm{AlMe}_{3}$ & $\mathrm{Me}$ & 92 \\
$\mathrm{AlEt}_{3}$ & Et & 82 \\
$\mathrm{AlEt}_{2} \mathrm{Cl}$ & $\mathrm{Et}$ & 85 \\
$\mathrm{AlEtCl}_{2}$ & $\mathrm{Et}$ & 81 \\
\hline
\end{tabular}

Table 8. TMSOTf-mediated addition of Reformatsky reagent on glycals

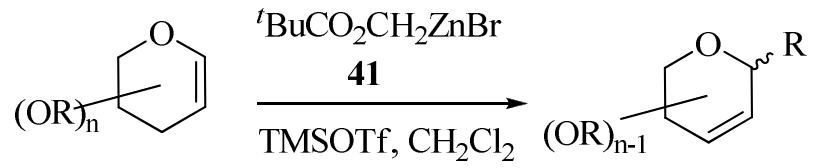

Yield (\%)

Alkylated zinc reagents have been reported by Gallagher et $a l^{25 a}$ for the Ferrier rearrangements on various protected glycals in the presence of $\mathrm{BF}_{3} . \mathrm{OEt}_{2}$ or TMSOTf as a Lewis acid. The reaction yielded the $\alpha$ anomer predominantly (Table 9). Attempts to utilise $\mathrm{Zn}(\mathrm{Cu})$ couple with alkyl halides for similar organometallic reaction in presence of Lewis acids resulted in the formation of C-3 substituted glycals. The authors have subsequently reported ${ }^{25 b}$ that alkylated zinc halides react with a $\beta$-selectivity similar to that earlier reported by Isobe $e t$ al. (Scheme 5, Figure 2), forming 44 from di- $O$-acetyl-D-xylal 18, as shown in Table 9. 
Table 9. Alkylated zincs as nucleophiles in the presence of $\mathrm{BF}_{3} \cdot \mathrm{OEt}_{2}$

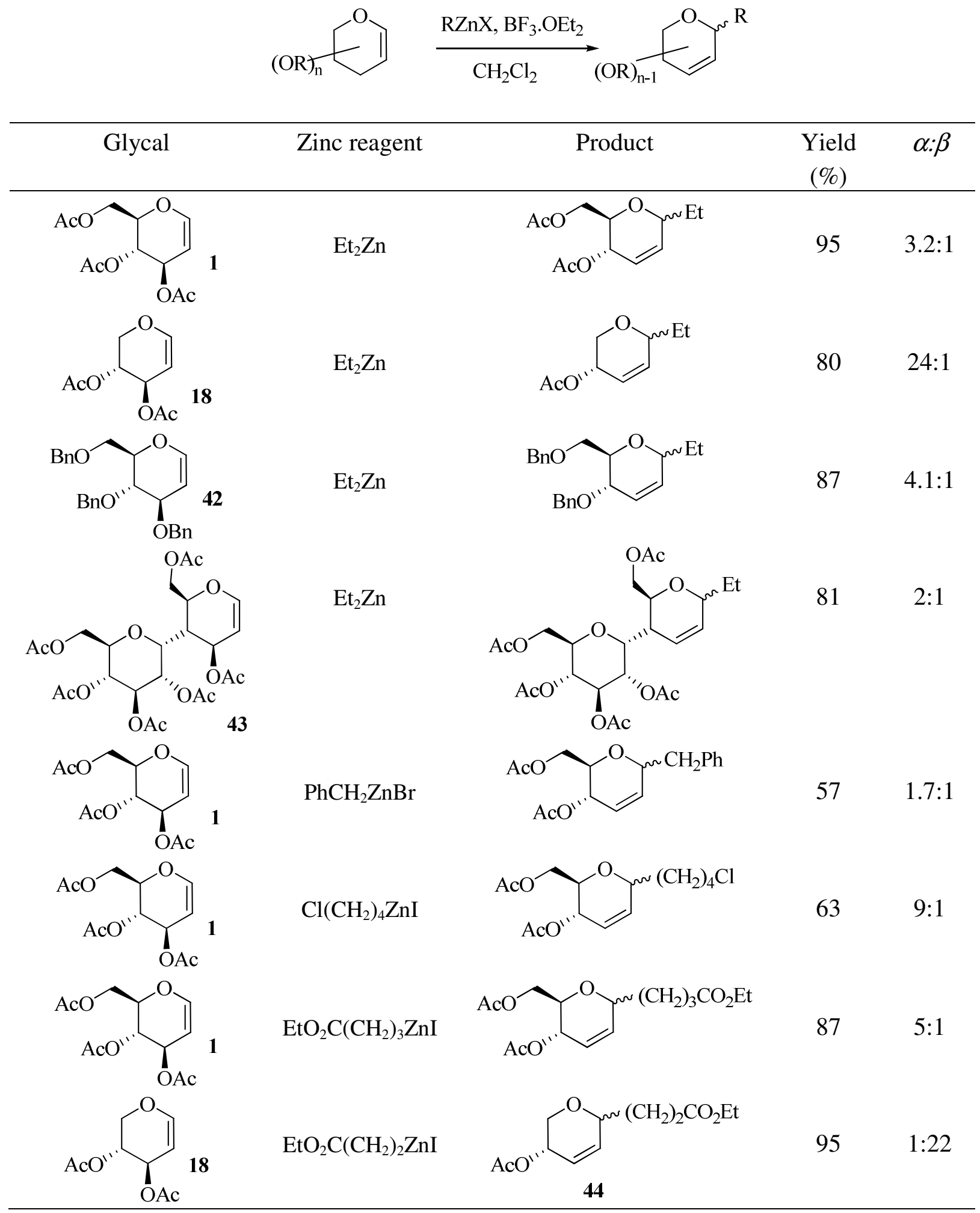


R.F.W. Jackson and co-workers ${ }^{26}$ reported the use of alkylated zinc/copper reagents on the novel tetra(isopropyl)disiloxane glucal derivative $\mathbf{4 5}$ bearing a leaving group at C-3 as shown in Scheme 21. $\beta$-Selectivity for both nucleophilic substitution at C-3 giving 46a, and Ferrier rearrangement at $\mathrm{C}-1$ resulting in $\mathbf{4 6 b}$ was observed. Several amino acid derived alkanes have been used as nucleophiles. Also, glutamic acid derived zinc reagent 47 when reacted with tri- $O$ acetyl-D-glucal 1 produced the C-1 adduct only 48 with $\alpha$-selectivity in the presence of $\mathrm{BF}_{3} \cdot \mathrm{OEt}_{2}$.

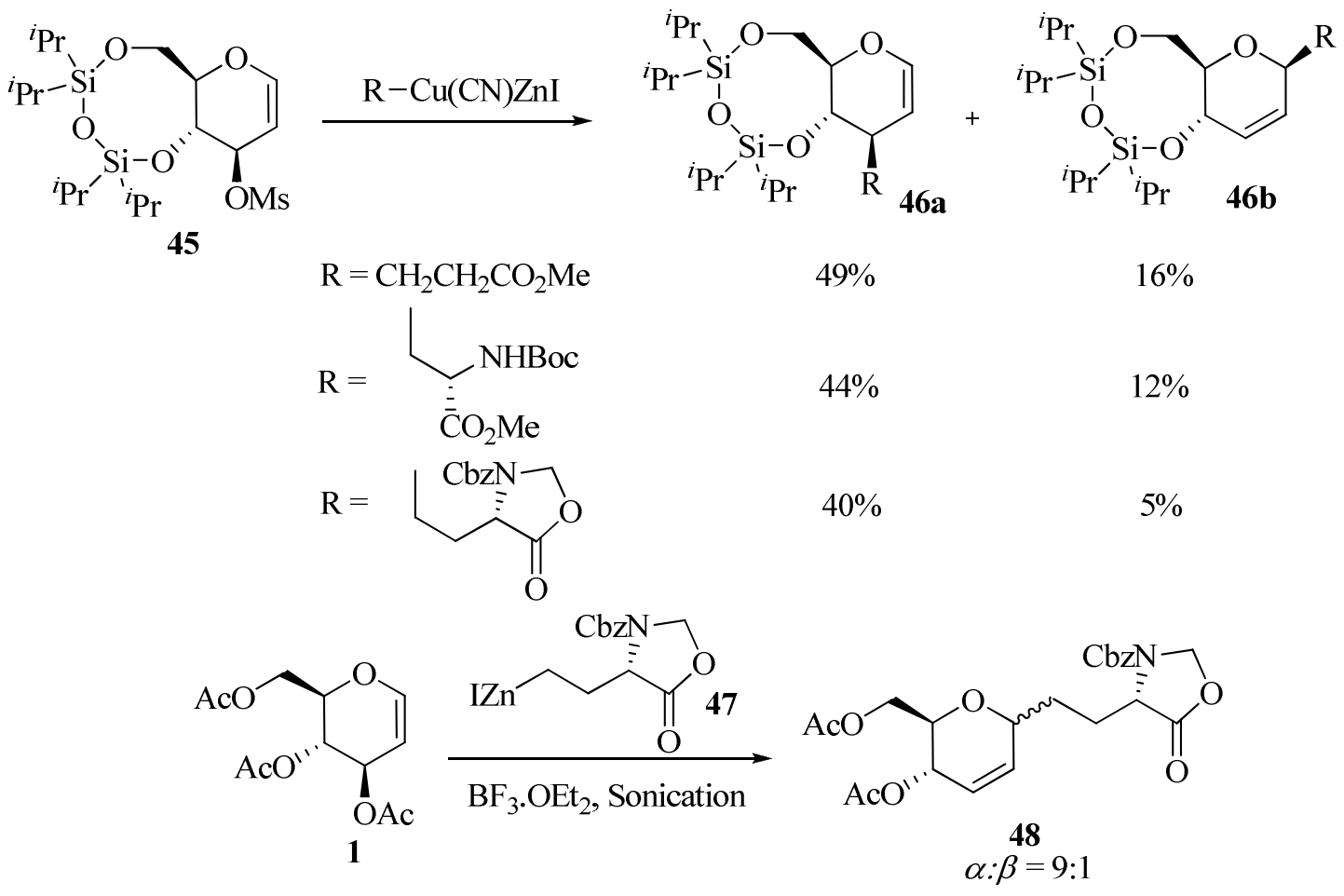

\section{Scheme 21}

Cossy and Rakotoarisoa ${ }^{27}$ reported efficient nucleophilic attack by alkyl copper reagents on $\mathrm{C}$-2-formylated tri-O-benzyl-D-glucal 49 in the presence of $\mathrm{BF}_{3} . \mathrm{OEt}_{2}$. The reactions were observed to be stereospecific, yielding only the $\alpha$ anomer of the Ferrier products 50 (Scheme 22 ). On the contrary, the glycals underwent a 1,4-Michael addition in the presence of lithium dialkyl cuprates with no elimination of the C-3 substituent to form adducts $\mathbf{5 1}$ without the activation with a Lewis acid. 


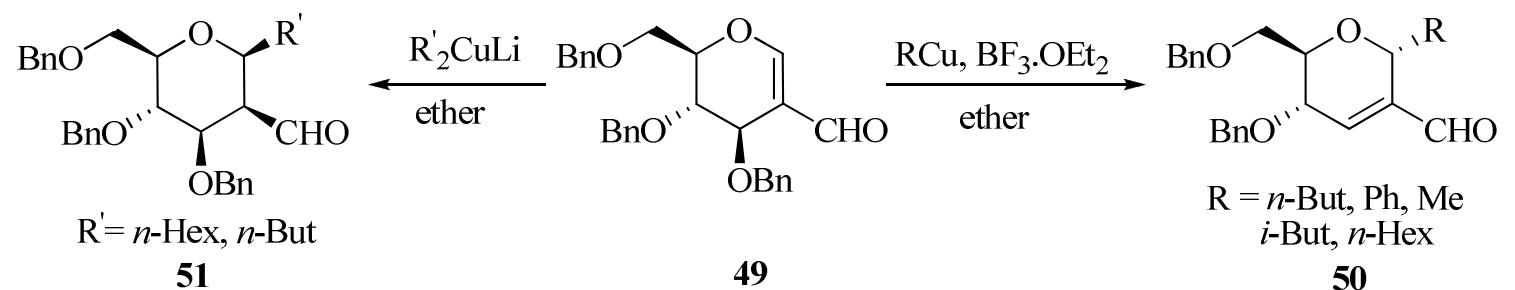

\section{Scheme 22}

Several $\sigma$-aryl-Pd compexes synthesized via transmetalation reaction between boronic acid and palladium (II) salt were observed to be efficient in carrying out Ferrier rearrangements on acetylated glycals. The reagent system, developed by Maddaford et al., ${ }^{28}$ produced the desired product with $\alpha$-selectivity on the D-glycal substrates (Scheme 23).<smiles>CC(=O)OC[C@H]1OC=C[C@@H](OC(C)=O)[C@@H]1OC(C)=O</smiles>

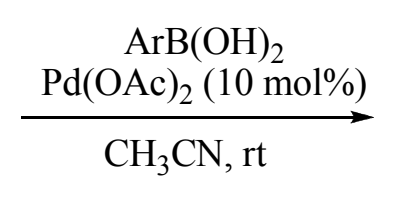

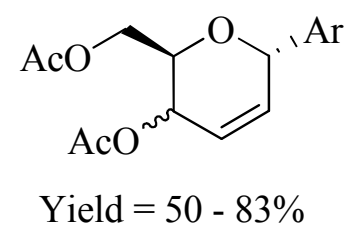<smiles>CC(=O)O[C@H]1C=CO[C@@H](C)[C@@H]1OC(C)=O</smiles>

11

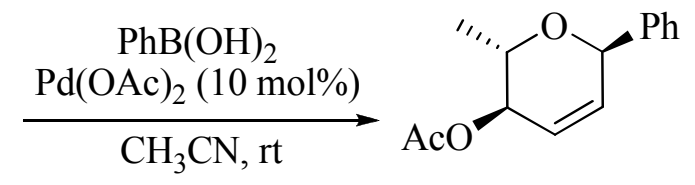

52

$\mathrm{Pd}(\mathrm{OAc})_{2}+\mathrm{PhB}(\mathrm{OH})_{2}$ $\mathrm{PhPd}(\mathrm{OAc})+(\mathrm{OAc}) \mathrm{B}(\mathrm{OH})_{2}$<smiles>CC(=O)OC[C@H]1OC=C[C@@H](OC(C)=O)[C@H]1COC(C)=O</smiles>

\section{Scheme 23}

The proposed mechanism involves syn addition of the in situ generated PhPdOAc from the $\alpha$-face of the glycal followed by anti elimination which results in the formation of $\operatorname{Pd}(\mathrm{OAc})_{2}$. When L-rhamnal diacetate $\mathbf{1 1}$ was subjected to the reagent system, the $\beta$-anomer $\mathbf{5 2}$ was obtained as the only product, thus supporting the proposed mechanism where the metal complex approaches from the less hindered face of the glycal. The reaction was successful with $10 \mathrm{~mol} \%$ of $\mathrm{Pd}(\mathrm{OAc})_{2}$ and electron withdrawing groups on the boronic acid reduced the yield of the reactions considerably. 
Du Bois and co workers ${ }^{29}$ have demonstrated the use of alkyl and aryl zinc reagents as efficient nucleophiles on 1,2-dihydropyranylacetate derivatives. Several phenyl and heteroarylzinc reagents were synthesized smoothly from the in situ generated lithiated aryl intermediates via transmetallation with $\mathrm{ZnCl}_{2}$ at $-78{ }^{\circ} \mathrm{C}$ as shown in Table 10. The Ferrier rearrangement proceeded with good stereoselectivity with preference for the $\alpha$-anomers at $25{ }^{\circ} \mathrm{C}$. Both electron donating and withdrawing groups on the phenyl ring furnished the desired products in comparable rates and yield. Correspondingly, the authors have generated alkylated zinc reagents using $\mathrm{Zn}(\mathrm{Cu})$ couple, $\mathrm{ZnCl}_{2}$, with DMA as an additive with alkyl iodides. The 1,2dihydropyranyl acetates reportedly underwent Ferrier rearrangement with these zinc intermediates to furnish trans-2,6-dialkyl-substituted pyrans.

Table 10. Alkyl and aryl iodides in the presence of $\mathrm{ZnCl}_{2}$

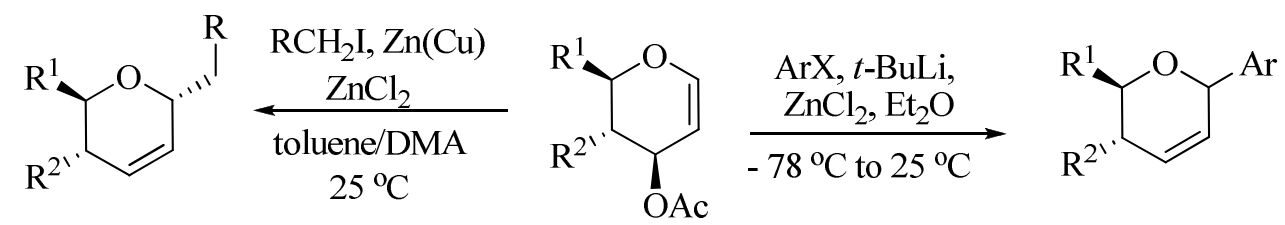

(n)


Table 10. Continued

\begin{tabular}{cccccc}
\hline $\mathrm{R} 1$ & $\mathrm{R} 2$ & $\mathrm{Ar} / \mathrm{R}$ & Product & $\begin{array}{c}\text { Yield } \\
(\%)\end{array}$ \\
\hline $\mathrm{CH}_{2} \mathrm{OTBS}$ & $\mathrm{H}$ & $\mathrm{I} \sim \mathrm{CO}_{2} \mathrm{Et}$ & & \\
$\mathrm{CH}_{2} \mathrm{CH}_{2} \mathrm{Ph}$ & $\mathrm{H}$ & $\mathrm{C}$ & &
\end{tabular}

Xue et al..$^{30}$ have reported the formation of alkyl $C$-pyranosides from dialkylated zincs, and aryl $C$-pyranosides from arylzinc halides, using trifluoroacetic acid and $\mathrm{BF}_{3} \cdot \mathrm{OEt}_{2}$, respectively (Table 11) in good yields with predominant $\alpha$-selectivity.

Table 11. Organozinc nucleophiles in the presence of $\mathrm{BF}_{3} \cdot \mathrm{OEt}_{2}$

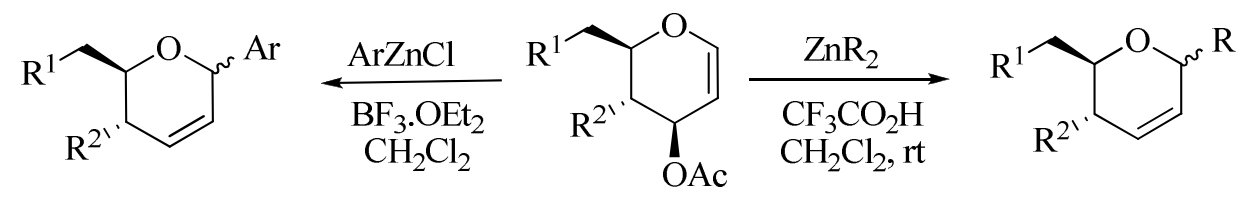

\begin{tabular}{ccccc}
\hline $\mathrm{R}^{1}$ & $\mathrm{R}^{2}$ & $\mathrm{R} / \mathrm{ArBr}$ & Yield (\%) & $\alpha: \beta$ \\
\hline $\mathrm{OAc}$ & $\mathrm{OAc}$ & $\mathrm{Me}$ & 97 & $2.3: 1$ \\
$\mathrm{OTBS}$ & $\mathrm{OAc}$ & $\mathrm{Ph}$ & 88 & $19: 1$ \\
$\mathrm{CH}_{2} \mathrm{Ph}$ & $\mathrm{H}$ & & 89 & $10: 1$ \\
$\mathrm{OAc}$ & $\mathrm{OAc}$ & & 97 & $7: 1$ \\
$\mathrm{OAc}$ & $\mathrm{OAc}$ & & & $7: 1$ \\
& & & &
\end{tabular}

Lubin-Germain et $a l .{ }^{31}$ reported the synthesis of alkynated pseudoglycosides catalysed by indium metal from the corresponding alkyne iodide in more than 9:1 stereoselectivity favoring the $\alpha$-anomer as shown in Table 12. The presence of the iodide functionality on the alkynes was found to be essential for the Ferrier reaction to occur. Indium metal was observed to be superior to other metals like zinc, manganese or their salts for product formation with better yields and selectivity. The trimethylsilylethynyl- $C$-glycoside was treated with silver nitrate and $\mathrm{N}$ iodosuccinimide to obtain the corresponding iodide which in turn was reacted with substituted 
glycals to give $C$-disaccharides. Glycals containing pivaloyl and benzyl protecting groups were also reported to undergo rearrangement under these conditions.

Table 12. Indium metal mediated carbon-Ferrier rearrangement

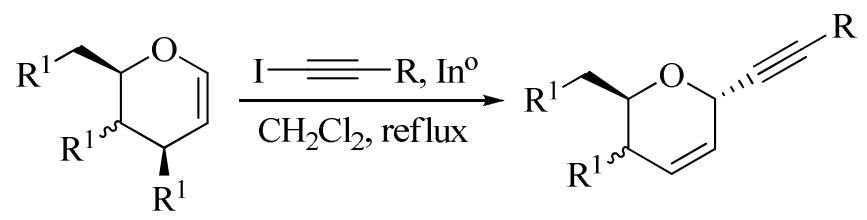

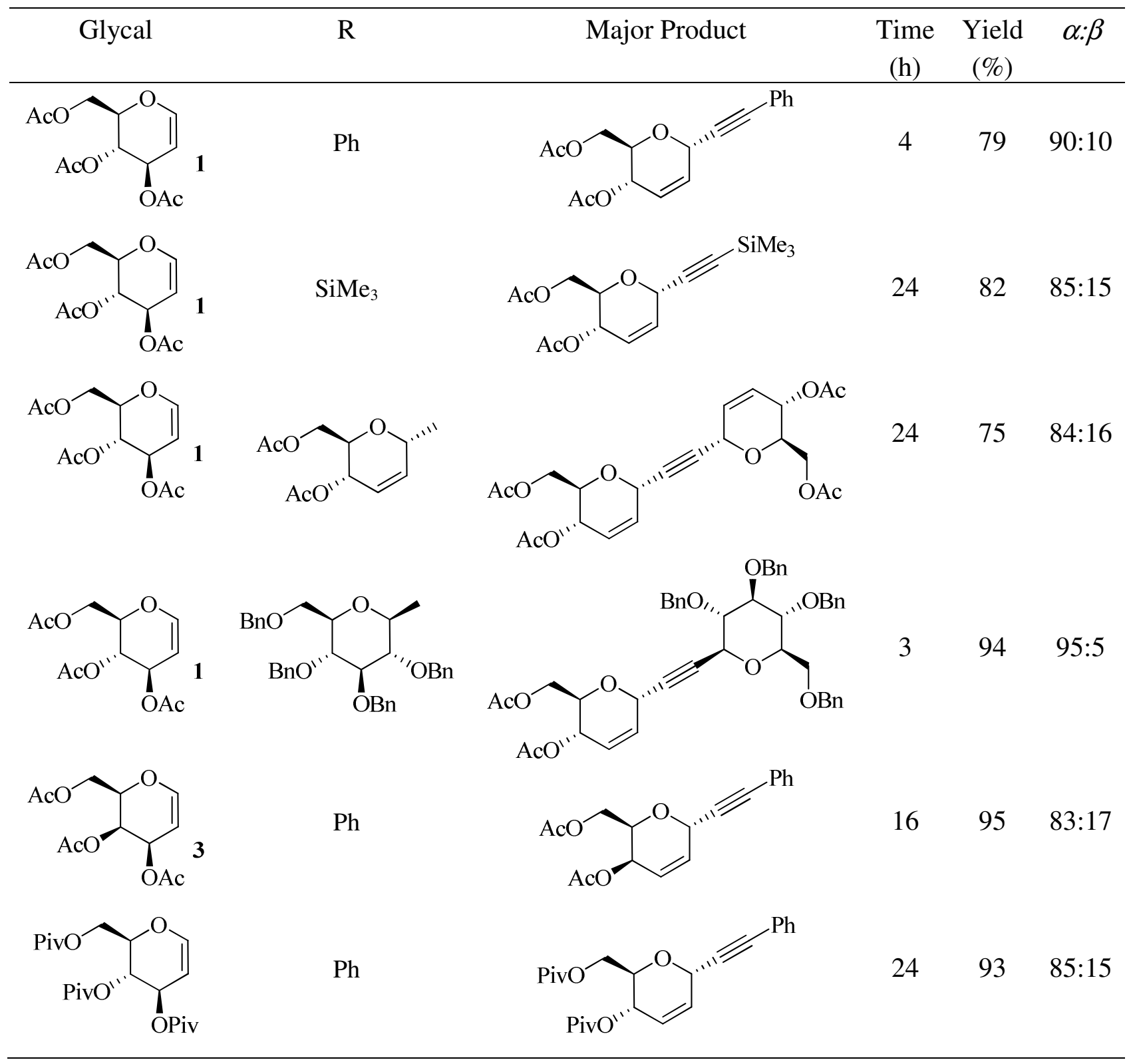


Table 12. Continued

Glycal

The above mentioned protocol has been employed by the same authors with Garner's aldehyde-derived alkynyl iodide but failed to provide the desired pseudoglycal (Scheme 24). ${ }^{32} \mathrm{~A}$ bicyclic alkene $\mathbf{5 3}$ was obtained, the formation of which has been suggested to be via indium mediated carbamate reduction followed by cyclization. On changing the amine protection from Boc to $o$-diphenylamide, Ferrier-rearranged products $\mathbf{5 4}$ were obtained in good yields.

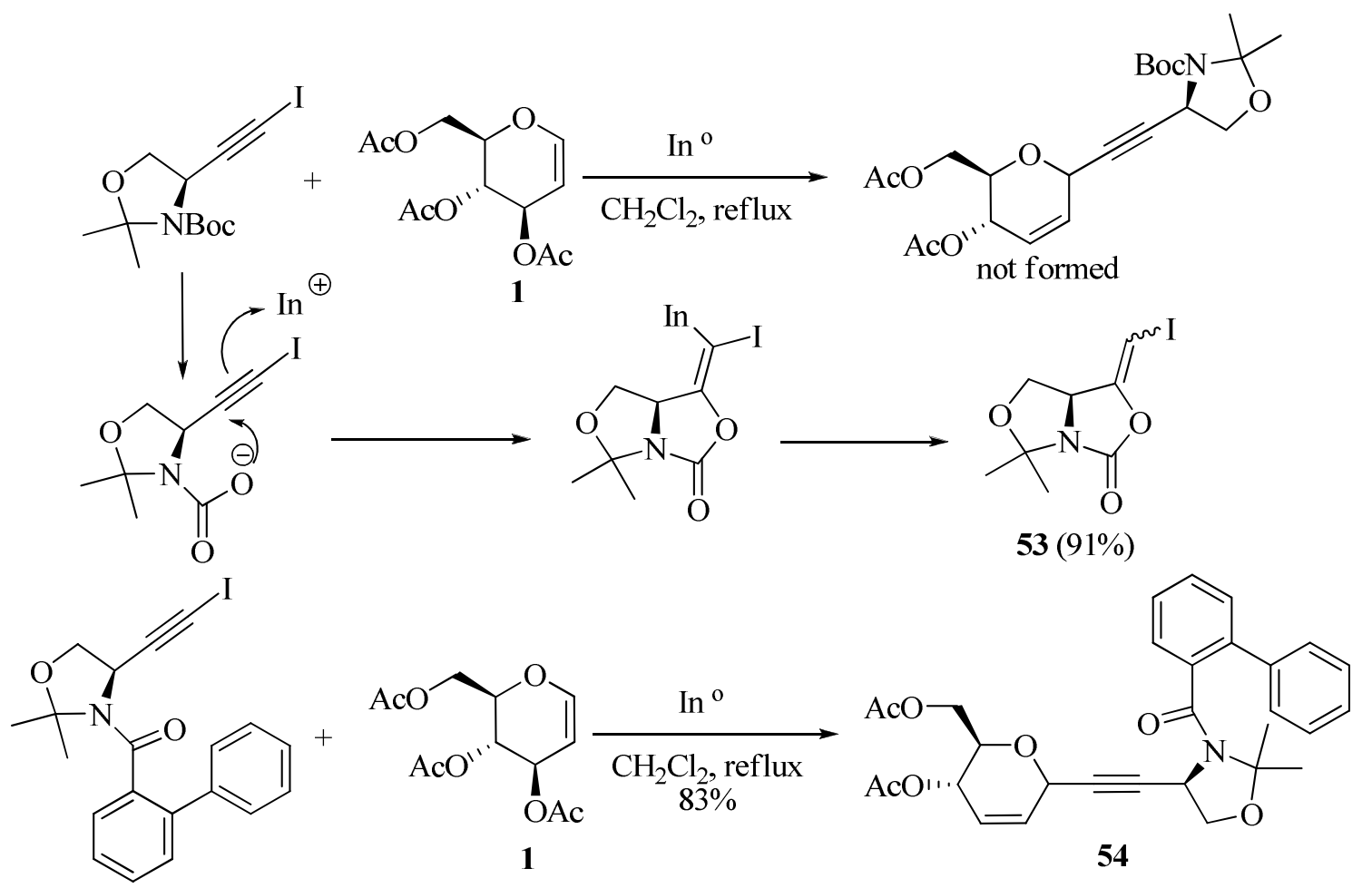

\section{Scheme 24}

\section{Propargyl or Alkynyl Silanes}

In a manner analogous to the allylsilane addition to the anomeric centre of D-hexopyranose rings, silylacetylenes were found to be reactive enough to generate the corresponding 'sugar 
acetylenes'. As mentioned earlier, Nicolaou et al. have explored the reaction of various nucleophiles on 1-substituted glycals 5 and 56 using 1 equiv. of $\mathrm{TiCl}_{4}{ }^{3}$ On reacting methyl trimethylsilyl acetylene with these substrates, they obtained products in good yields in a highly stereospecific manner (Scheme 25). Utilising this protocol, many 1,1-disubstituted glycosides 55 and 57 respectively have been obtained.

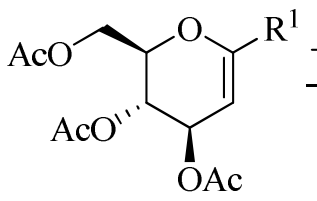

5: $\mathrm{R}^{1}=\mathrm{Me}$

56: $\mathrm{R}^{1}=$ allyl

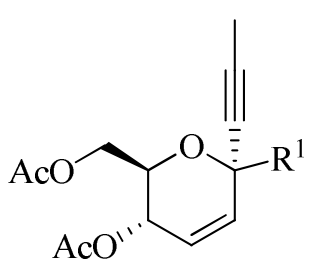

55: $\mathrm{R}^{1}=\mathrm{Me}$

57: $\mathrm{R}^{1}=$ allyl

\section{Scheme 25}

During the course of their study towards the synthesis of okadaic acid, Isobe et al. ${ }^{4}$ explored the $C$-glycosidation on glycals with silyl acetylenes instead of the usual allylsilanes using $\mathrm{TiCl}_{4}$ (Scheme 26). Interestingly, the stereoselectivity of this reaction was observed to be excellent, yielding only the $\alpha$-anomer 58, as compared to the 16:1 ratio of isomers in the case of allylsilanes. $^{2}$ Other nucleophiles such as trimethylphenylsilane, trimethylvinylsilane, ethynyltrimethylsilane and dihydropyran failed to react owing to the rapid polymerisation of glucal 1. In their next report, Isobe et al. ${ }^{33 a}$ carried out the glycosylation studies on tri- $O$-acetylD-glucal 1 with bistrimethylacetylenes, under the influence of $\mathrm{SnCl}_{4}$, to obtain the product 58 in quantitative yield. The same reaction was performed with tributylstannyl- and trimethylsilylacetylene using $\mathrm{TiCl}_{4}$ in high yields. The noteworthy fact is the observation of complete stereoselectivity in all examples.

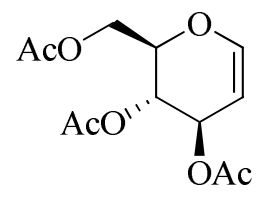

1

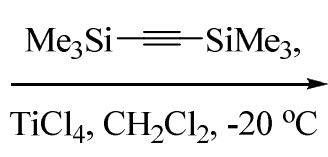

$\mathrm{TiCl}_{4}, \mathrm{CH}_{2} \mathrm{Cl}_{2},-20^{\circ} \mathrm{C}$

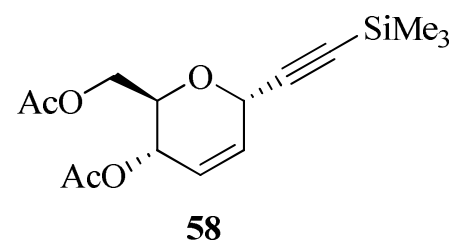

\section{Scheme 26}

Similar $C$-glycosidation on 2-acetoxy-D-glucal 59 with $\mathrm{SnCl}_{4}$ proceeded to give products 60 which were unstable (Scheme 27) and were converted into $\alpha, \beta$-unsaturated ketones 61 on aqueous workup, and reduced using $\mathrm{NaBH}_{4}$ or $\mathrm{LiAlH}_{4}$ to give allylic alcohols 62 for analysis.

Isobe et al. were able to isolate some of the doubly glycosidated product $\mathbf{6 5}$ (Scheme 28), from the reaction of the ene diyne nucleophile $\mathbf{6 3}$ with glucal 1, albeit in only $10 \%$ yield with $20 \%$ conversion of the starting monoglycosylated compound 64. Moreover, the reaction was unsuccessful in other cases. 


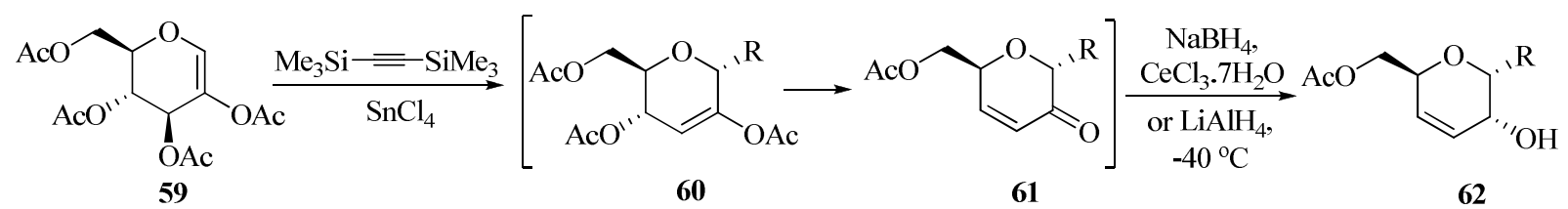

Scheme 27

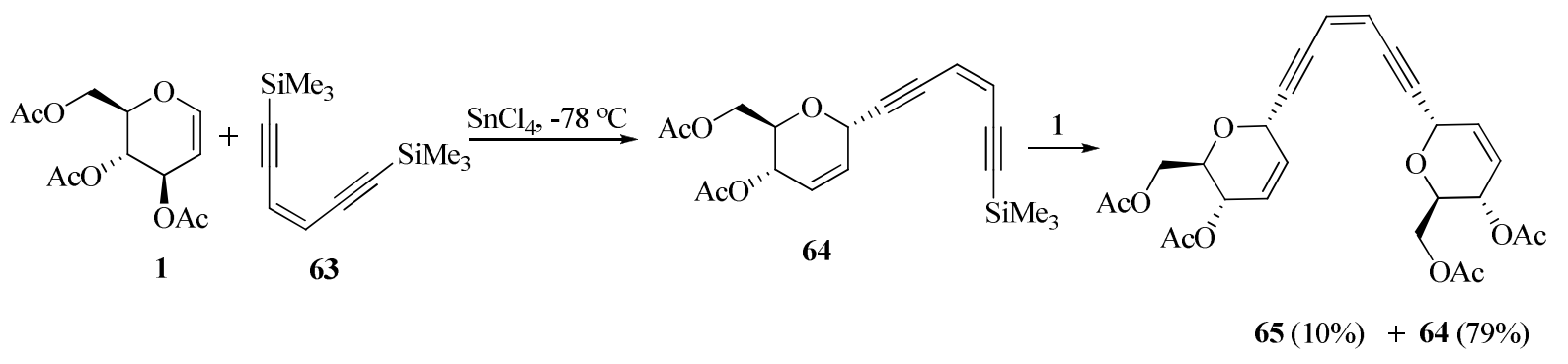

\section{Scheme 28}

Later, the same group attempted double glycosidation using bistrimethylsilylacetylene on glucal triacetate 1 in the presence of $\mathrm{SnCl}_{4}$, but failed. ${ }^{34}$ However, glucal 1 on reaction with 1,4bis(trimethylsilyl)-1,3-butadiyne 66 with $1 \% \mathrm{SnCl}_{4}$ at $0{ }^{\circ} \mathrm{C}$ in 3 hours led to the second glycosidation product $\mathbf{6 8}$ in $55 \%$ yield along with $19 \%$ of the monoglycosylated product $\mathbf{6 7}$ (Scheme 29). Bis-glycosylated product 68, on the other hand, was obtained in one pot without isolating the intermediate in 54\% yield by further treatment with 1 in presence of $\mathrm{SnCl}_{4}$. The same reaction was observed with the glucal derivative 59 but the yields were not very encouraging. Furthermore, similar reaction employing 1,6-bis(trimethylsilyl)-hex-3-en-1,5-diyne 63 and glucal acetate 1 gave the monoglycosylated product 64 in just $1.25 \mathrm{~h}$ in $79 \%$ yield, and the bis-glycosylated product $\mathbf{6 5}$ in $68 \%$, without isolating the intermediate. The second glycosidation took place faster in this case. In all the reactions, the acetylenic group entered in $\alpha$ orientation with exclusive regio- and stereoselectivity.

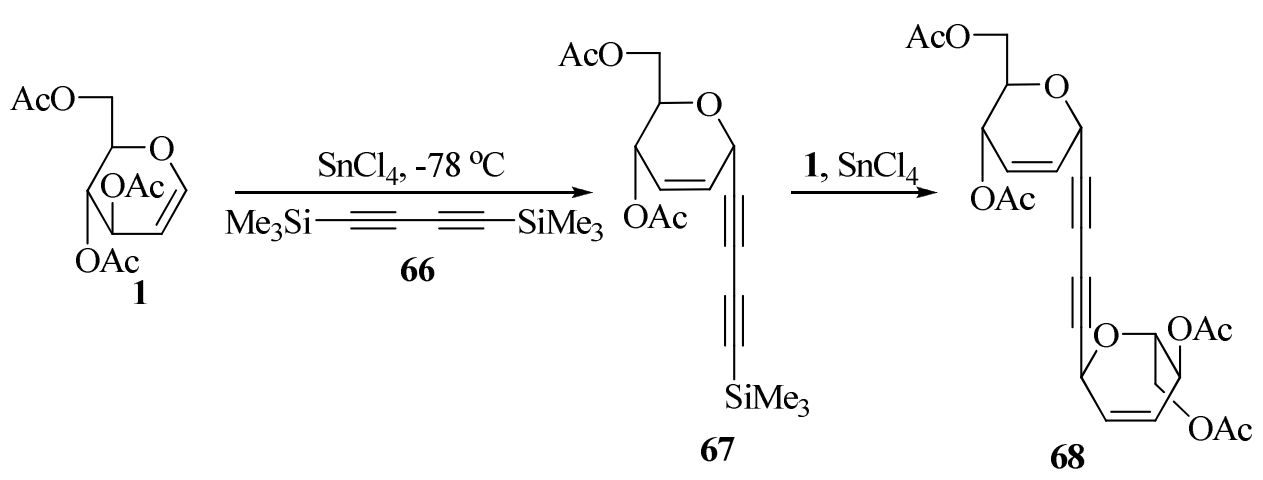

Scheme 29 
Isobe et $a l .{ }^{9}$ went on to expand the scope of acetylenic glycosylations on pentopyranose derivatives such as di-O-acetyl-D-xylal 18 and di-O-acetyl-D-arabinal 19 (Scheme 30). The reaction was carried out with bistrimethylsilylacetylene using $\mathrm{TiCl}_{4}$ at $-40{ }^{\circ} \mathrm{C}$. In striking contrast to the observations for glucal $\mathbf{1}$, the product in these cases bore predominantly 1,4-anti stereochemistry. The products 69 and 70 exhibited the same optical rotation with opposite sign proving that they were enantiomers of each other. Several other nucleophiles such as $\mathrm{Me}_{3} \mathrm{Si}$ $\mathrm{C} \equiv \mathrm{C}-\mathrm{R}$, where $\mathrm{R}=\mathrm{Me}$, SPh, etc. were also used.

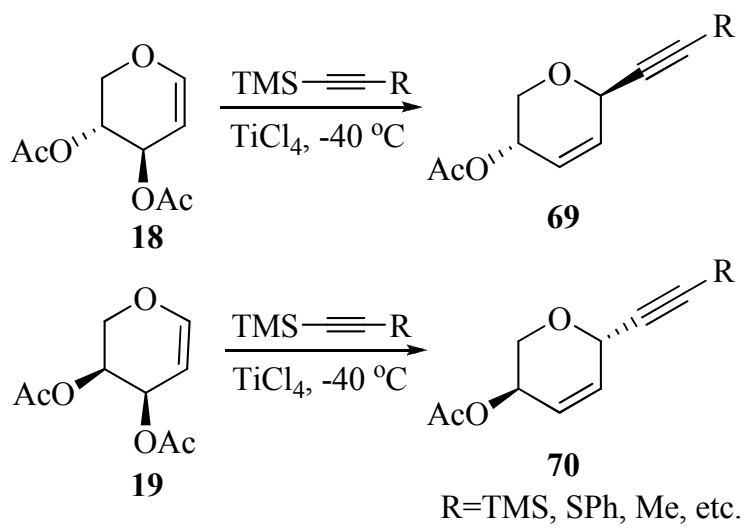

\section{Scheme 30}

The stereochemical outcome was rationalised as a consequence of the stereoelectronic effect, as discussed earlier, vide supra (see Figure 2), while dealing with similar reactions using allyl trimethylsilane.

In the same year, Vogel ${ }^{35 a}$ and Isobe ${ }^{35 b}$ reported for the first time the reaction of glucal 1 with propargyltrimethylsilane and obtained $\alpha$-C-allenyl product 71. Vogel et al. performed the reaction in $\mathrm{CH}_{3} \mathrm{CN}$ using TMSOTf as a catalyst, as part of a disaccharide synthesis (Scheme 31).

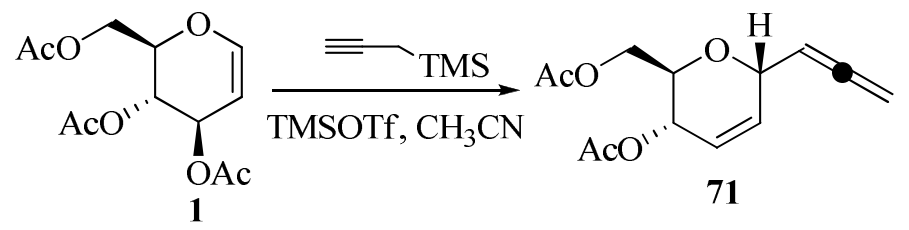

\section{Scheme 31}

Isobe's group carried out the same reaction with 1.5 equiv. of propargyltrimethylsilane in dichloromethane at $-20{ }^{\circ} \mathrm{C}$ (Scheme 32). By using $\mathrm{SnCl}_{4}$ as a catalyst, they reported $83.3 \%$ yield, whereas by using $\mathrm{TiCl}_{4}$, the yield increased slightly to $88.5 \%$. Reaction of propargyl silane with tri- $O$-acetyl-D-galactal 3 under the influence of $\mathrm{SnCl}_{4}$ or $\mathrm{TiCl}_{4}$, gave the $\alpha$-C-allenyl product 72 in 81.6 or $75.7 \%$ yield respectively. Surprisingly the same reaction with $2,3,4,5$-tetra- $O$-acetyl-Dgalactal 59, followed by reduction gave a mixture of $\alpha$ - and $\beta$-allenyl products $\mathbf{7 3}$ and 74 in 7.3:1 ratio with $\mathrm{SnCl}_{4}$ and 5.2:1 in the case of $\mathrm{TiCl}_{4}$ (Scheme 33). 


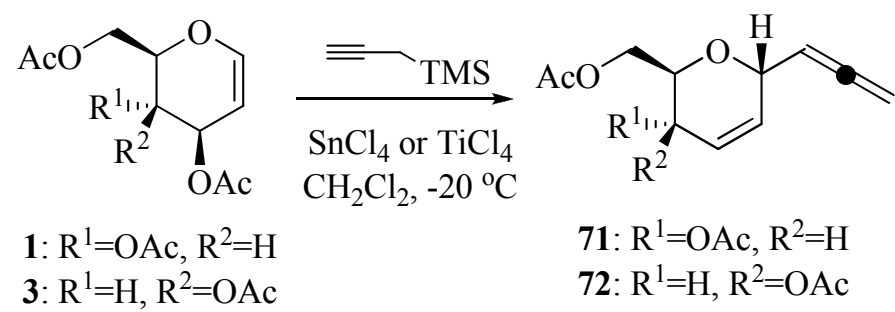

Scheme 32<smiles>CC(=O)OC[C@H]1OC=C(OC(C)=O)[C@@H](OC(C)=O)[C@H]1OC(C)=O</smiles>

59

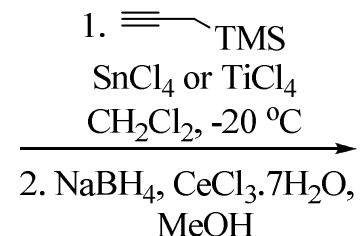

$\mathrm{MeOH}$

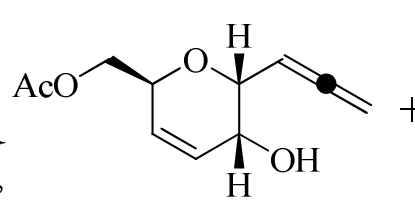

73<smiles>C=C=C[C@H]1O[C@@H](COC(C)=O)C=C[C@H]1O</smiles>

74

\section{Scheme 33}

Yadav et al. ${ }^{36}$ reported $C$-alkynylation of glycals 75 with the much milder Lewis acid $\operatorname{InBr}_{3}$ (Scheme 34). Employing only $5 \mathrm{~mol} \%$ of the catalyst, they obtained very good yields of 76 in shorter reaction time, with high anomeric selectivity, and recoverability of the catalyst. Other Lewis acids were also tried, such as $\mathrm{InCl}_{3}, \mathrm{In}(\mathrm{OTf})_{3}, \mathrm{Sc}(\mathrm{OTf})_{3}, \mathrm{~Tb}(\mathrm{OTf})_{3}, \mathrm{YCl}_{3}$ and $\mathrm{YbCl}_{3}$, but $\mathrm{InBr}_{3}$ gave the best results in terms of conversion and selectivity. As earlier, 1,4-anti selectivity was observed in the case of pentose sugars.

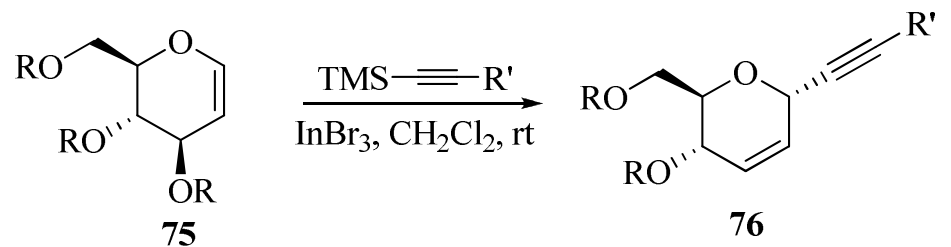

$\mathrm{R}=$ Ac, Piv, Me, Bn, Allyl

$\mathrm{R}^{\prime}=\mathrm{Ph}, \mathrm{TMS}$, propyl, pentyl, etc.

\section{Scheme 34}

Iodine was found to catalyse the $C$-glycosidation of tri- $O$-acetyl-D-glucal 1 with various silylacetylenes at room temperature, in high yield (Scheme 35). ${ }^{37}$ Optimum conditions for this reaction were investigated and it was found that 1 equiv. of $\mathrm{I}_{2}$ in $\operatorname{dry} \mathrm{CH}_{2} \mathrm{Cl}_{2}$, with 2 equiv. of

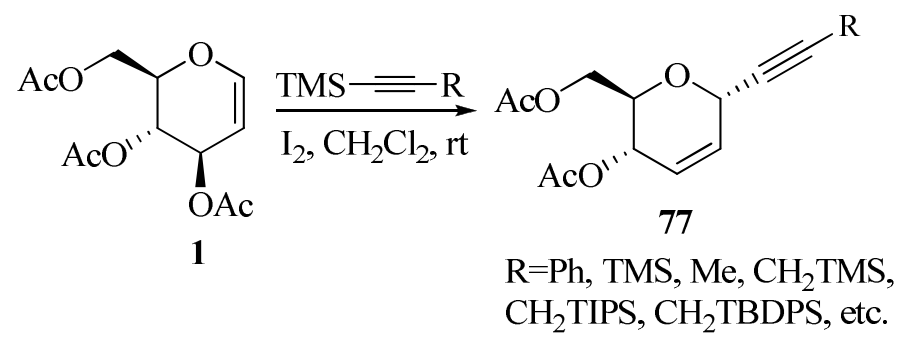

\section{Scheme 35}


acetylene nucleophile was effective for this reaction. In agreement with previous observations, the stereochemistry at the C-1 position in the product 77 was exclusively $\alpha$ orientation.

Isobe et $a l .{ }^{38}$ then carried out a comparative study of the reactivity of alkynyl and propargyl silanes. The nucleophile $\mathbf{7 8}$ containing both propargyl and alkynyl moieties was of interest since it is suitable for the evaluation of reactivities of both groups under the same conditions. In the reaction between 1,3-bis(trimethylsilyl)propyne $\mathbf{7 8}$ and glucal $\mathbf{1}$, a mixture of allene $\mathbf{7 9}$ and alkyne 80 was obtained in 1:2.5 ratio (Scheme 36) using $\mathrm{SnCl}_{4}$ as a Lewis acid. The ratio was found inverted to $4: 1$, on changing the solvent from dichloromethane to acetonitrile. The reason for the reversal of ratio was proposed to be due to the stabilisation of the cationic intermediate by acetonitrile (Figure 3). Different substrates with different silyl groups were investigated. In the silyl nucleophile with 2 triisopropylsilyl groups, no reaction took place. With triisopropylsilyl group in the propargylic position, the alkyne product $\mathbf{8 1}$ was obtained exclusively. When the triisopropylsilyl group was in the acetylenic position, the major product was found to be the propargylic compound 83, along with a small amount of allenic product 82. On changing the medium of reaction from dichloromethane to acetonitrile, the formation of $\mathbf{8 3}$ was favoured.

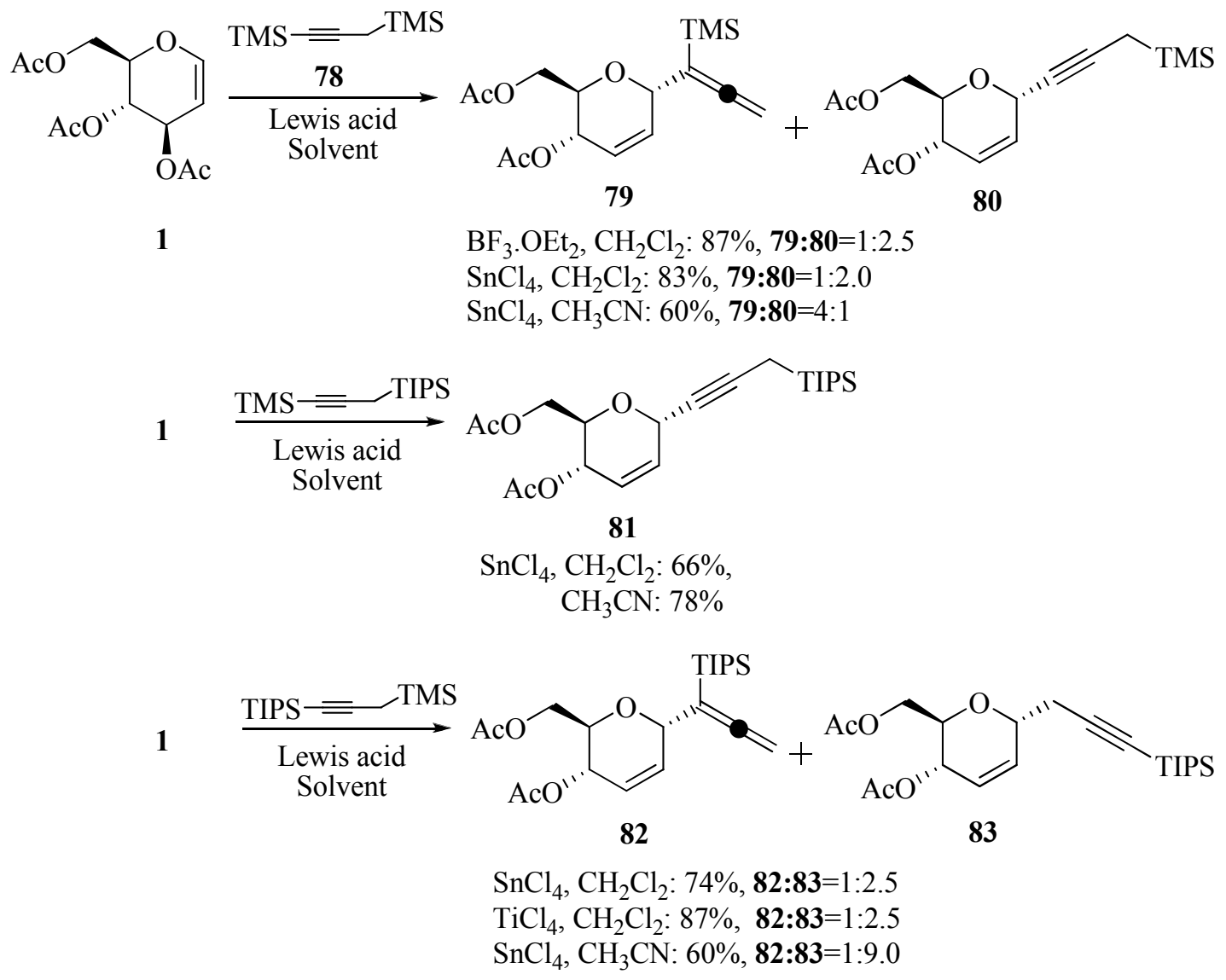

\section{Scheme 36}




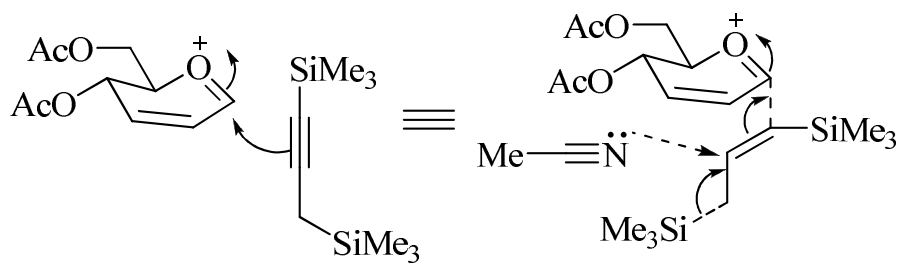

\section{Figure 3}

In a study of the carbon-Ferrier rearrangement in an ionic liquid [bmim] $\left[\mathrm{BF}_{4}\right]$ using $\mathrm{Yb}(\mathrm{OTf})_{3}$ as a catalyst (only $\left.5 \mathrm{~mol} \%\right)^{12 \mathrm{c}}$ tri- $O$-acetyl-D-glucal 1 underwent reaction with propargylsilane in 8 hours to give $65 \%$ of the $\alpha$-anomer 71 as the only product (Scheme 37).

A new nucleophile, 1,4-bis(trimethylsilyl)-2-butyne 84 was introduced by Isobe et al. ${ }^{39}$ that reacted with glucal $\mathbf{1}$ in the presence of $\mathrm{BF}_{3} \cdot \mathrm{Et}_{2} \mathrm{O}$, to give silylallene glycoside $\mathbf{8 5}$ with $\alpha$ orientation (Scheme 38). On reacting 2 equiv. of the glucal with 1 equiv. of nucleophile using $\mathrm{BF}_{3}$. Et $\mathrm{H}_{2} \mathrm{O}$ provided a new symmetrical diene glycoside $\mathbf{8 6}$ along with monoglycosidation product 85. Changing the Lewis acid to TMSOTf or $\mathrm{SnCl}_{4}$ did not improve yields of the reaction. However, when 3 equiv. of $\mathbf{1}$ were used under the influence of $\mathrm{SnCl}_{4}$, the diene glycoside $\mathbf{8 6}$ was obtained in $92 \%$ yield in just 15 minutes. In a similar manner, other symmetrical and unsymmetrical diene glycosides were prepared using this method.<smiles></smiles>

1

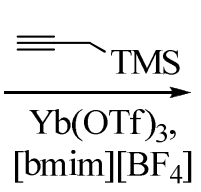

$[\mathrm{bmim}]\left[\mathrm{BF}_{4}\right]$<smiles>C=C=C[C@H]1C=C[C@@H](OC(C)=O)[C@@H](COC(C)=O)O1</smiles>

71

\section{Scheme 37}

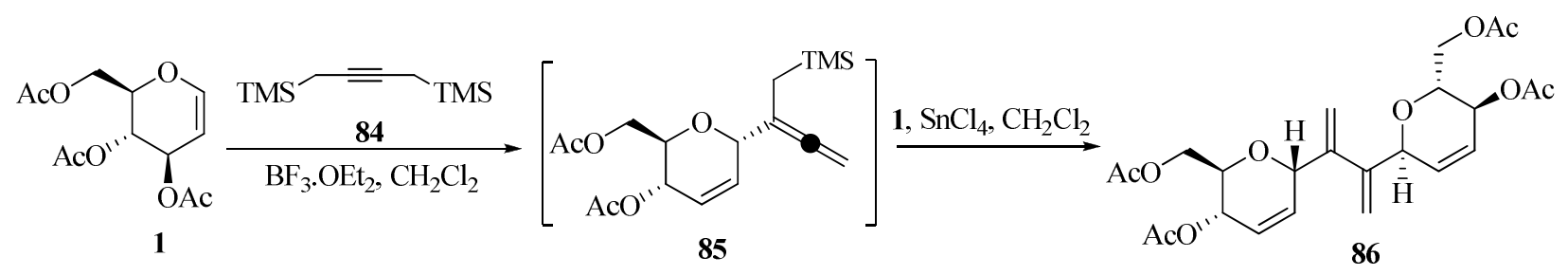

Scheme 38

In a detailed investigation of acid-catalysed glycosidation of endo- and exo-glycals using TFA, ${ }^{15 a}$ different nucleophiles were allowed to attack glycal, among which propargylsilane reacted with the galactal $\mathbf{8 7}$ to give sugar allene $\mathbf{8 8}$ in $\mathbf{7 9 \%}$ yield (Scheme 39 ).

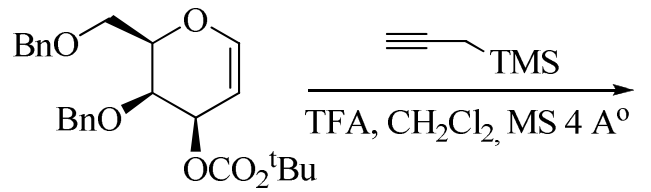

87<smiles>C=C=C[C@H]1C=C[C@@H](OBr)[C@@H](COBr)O1</smiles>

88

Scheme 39 
Procopio and co-workers ${ }^{16}$ explored the catalytic action of $\operatorname{Er}(\mathrm{OTf})_{3}$ on the $C$-glycosidation of glycals with various nucleophiles. In a typical reaction, $3 \mathrm{~mol} \%$ of $\operatorname{Er}(\mathrm{OTf})_{3}$ was sufficient to catalyse the $C$-Ferrier rearrangement using the propargyltrimethylsilanes or 1-phenyl-2(allyltrimethylsilyl)acetylene (Scheme 40). Mostly the reaction yielded exclusively $\alpha$-oriented products, but in the case of 3,4-di- $O$-acetyl-6-deoxy-L-glucal, $\beta$-oriented products were major.
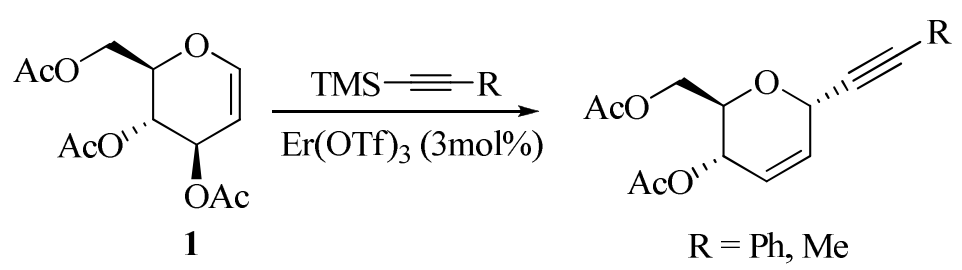

\section{Scheme 40}

\section{Silyl Cyanides}

Glycosyl cyanides are important intermediates in the synthesis of C-glycosyl derivatives, since the cyano group can be easily converted into other functional groups. The first Lewis-catalysed addition of trimethylsilyl cyanide (TMSCN) on glycals was reported by De Las Heras et al. in $1983 .^{40}$ The reaction on $\mathbf{1}$ was carried out in nitromethane as a solvent in the presence of a catalytic amount of $\mathrm{BF}_{3} . \mathrm{OEt}_{2}$, yielding $89 \mathrm{a}$ and $\mathbf{8 9 b}$ in 57 and $42 \%$ yields respectively (Scheme 41). The same reaction on glucal derivative 59 afforded a mixture of $\alpha$-and $\beta$ - anomers $90 \mathbf{a}$ and 90b in 46 and $34 \%$ yields respectively. The reaction was better than that using Lewis acid and sodium cyanide, in terms of yields and reaction conditions.

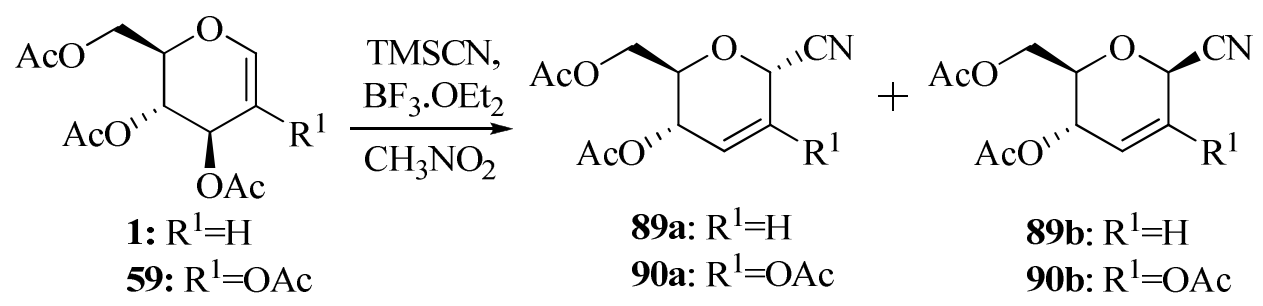

\section{Scheme 41}

Nicolaou et al., in their earlier report, ${ }^{3}$ also carried out the reaction of 1-alkylated glycals 5 with TMSCN using $\mathrm{TiCl}_{4}$, and observed the formation of $82 \%$ of exclusively $\alpha$-anomer $\mathbf{9 1}$, along with $11 \%$ of the isocyanide 92 (Scheme 42).<smiles>CC(=O)OC[C@H]1OC(C)=C[C@H](OC(C)=O)[C@H]1C(C)=O</smiles>

5

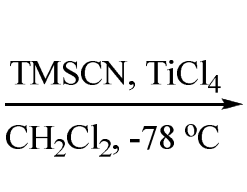

${ }^{\circ} \mathrm{C}$<smiles>CC(=O)OC[C@H]1O[C@](C)(C#N)C=C[C@@H]1C(C)=O</smiles>

91

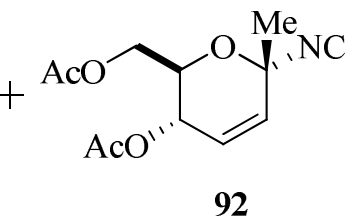

92

\section{Scheme 42}


During the synthesis of streptazolin, Kozikowski and Park ${ }^{5}$ investigated a Ferrier-type reaction on piperidinol 9 with various nucleophiles. The reaction of 9 with 6 equiv. of TMSCN, in the presence of TMSOTf (1.5 equiv.) at $-78{ }^{\circ} \mathrm{C}$ afforded the product 93 in 3 hours in $70 \%$ yield (Scheme 43). As expected, nucleophilic attack on the pyridinium ion occurred at the site $\alpha$ to the ring nitrogen atom.

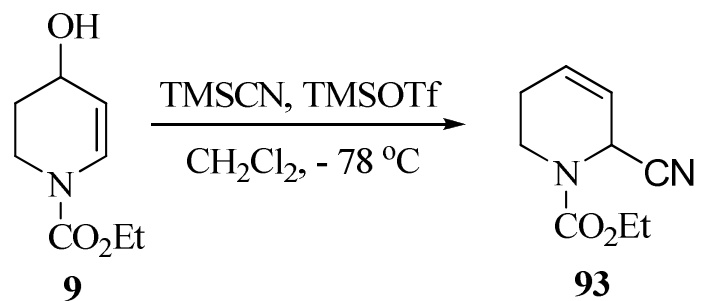

\section{Scheme 43}

The first example of a $C$-Ferrier rearrangement on acetylated and unprotected glycals without a catalyst, under thermal conditions, was reported by Hayashi's group. ${ }^{41}$ The reaction of TMSCN on glucal 1 at $80{ }^{\circ} \mathrm{C}$, remarkably gave 95\% yield of a 58:42 mixture of $\alpha$ - and $\beta$-glycosyl cyanides 89a and 89b (Scheme 44). Similarly, unprotected glucal 15 in the absence of solvent and catalyst was found to react with TMSCN to give products 94a and 94b in 74:26 ratio, in $84 \%$ yield. 2-bromo-D-glucal 95 reacted under the same conditions to yield $72 \%$ of a $4: 1$ ratio of $96 \mathbf{a}$ and $96 \mathbf{b}$.

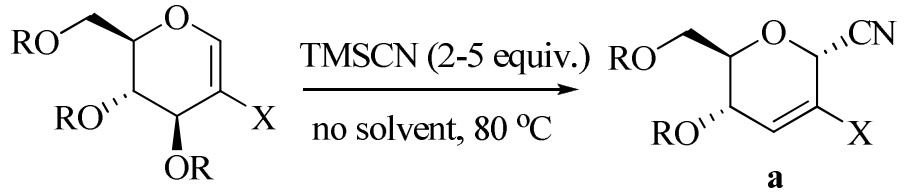

1: $\mathrm{R}=\mathrm{Ac}, \mathrm{X}=\mathrm{H}$

15: $\mathrm{R}=\mathrm{H}, \mathrm{X}=\mathrm{H}$

95: $\mathrm{R}=\mathrm{Ac}, \mathrm{X}=\mathrm{Br}$

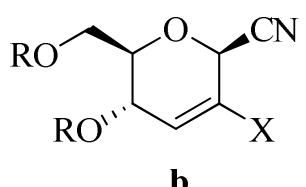

89: $\mathrm{R}=\mathrm{Ac}, \mathrm{X}=\mathrm{H}$

94: $\mathrm{R}=\mathrm{H}, \mathrm{X}=\mathrm{H}$

96: $\mathrm{R}=\mathrm{Ac}, \mathrm{X}=\mathrm{Br}$

\section{Scheme 44}

Yadav et al. ${ }^{11 \mathrm{a}}$ reported the treatment of glycals with various silyl nucleophiles in the presence of only $3 \mathrm{~mol} \%$ of $\mathrm{Sc}(\mathrm{OTf})_{3}$, to afford the corresponding 2,3-unsaturated $\mathrm{C}$-glycosides in excellent yields with $\alpha$-selectivity. Thus, for example, TMSCN reacted with $\mathbf{1}$ leading to 89 in $90 \%$ yield and the anomers were formed in 6:4 ratio (cf. Table 13, entry 1). Several glycals were successfully employed for this reaction. $\mathrm{Sc}(\mathrm{OTf})_{3}$ proved to be an efficient and reusable catalyst for this reaction, along with milder reaction conditions, lower catalyst usage and simple experimental procedure. Again the same group investigated the catalytic action of iodine on the addition of cyanide to glycals. ${ }^{1 \mathrm{~b}}$ Only $8 \mathrm{~mol} \%$ of iodine was found to be sufficient to catalyse the reaction of glucal 3 with TMSCN in 12 hours, yielding a 6:4 mixture of $\alpha$ - and $\beta$-cyanides in $80 \%$ yield, while galactal 18 gave 7:3 ratio of $\alpha$ - and $\beta$-cyanides in $72 \%$ yield (Table 13, entries 2 and 3). The same group ${ }^{11 \mathrm{c}}$ later explored the $\mathrm{InBr}_{3}$-catalysed Ferrier rearrangement of glucal 3 
with TMSCN at ambient temperature and obtained high yields and good selectivity (Table 13, entries 4 and 5 ) of the cyano product. In a similar manner, $\mathrm{Bi}(\mathrm{OTf})_{3}$ was employed in the $C$ Ferrier rearrangement of glycals. ${ }^{1 \mathrm{~d}} \mathrm{Bi}(\mathrm{OTf})_{3}$, being inexpensive and easy to prepare on gramscale in laboratory conditions, provided a convenient alternative to other lanthanide-based Lewis acids used for this reaction. Only 2 mol\% of the catalyst with 1.25 equiv. of TMSCN afforded a 7:3 mixture of cyanides in excellent yields (Table 13, Entry 6).

Table13. Lewis acid mediated $C$-glycosyl cyanide formation

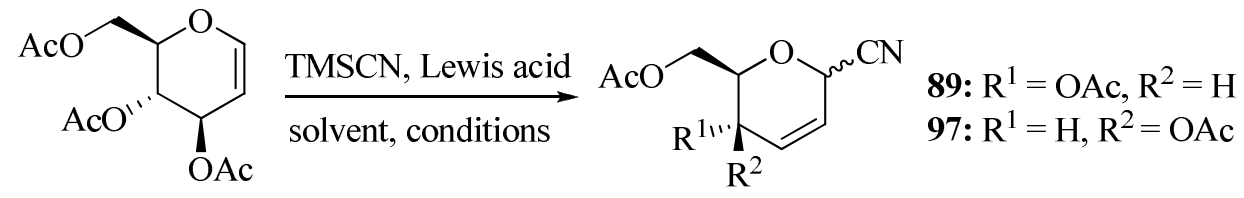

\begin{tabular}{cccccccc}
\hline Entry & Glycal & Lewis Acid & Solvent & Yield & $\alpha: \beta$ & Product & Ref. \\
\hline 1 & $\mathbf{1}$ & $\mathrm{Sc}(\mathrm{OTf})_{3}, 3 \mathrm{~mol} \%$ & $\mathrm{CH}_{2} \mathrm{Cl}_{2}, \mathrm{rt}$ & 90 & $6: 4$ & 89 & $11 \mathrm{a}$ \\
2 & $\mathbf{1}$ & $\mathrm{I}_{2}, 8 \mathrm{~mol} \%$ & $\mathrm{CH}_{2} \mathrm{Cl}_{2}, \mathrm{rt}$ & 80 & $6: 4$ & 89 & $11 \mathrm{~b}$ \\
3 & $\mathbf{3}$ & $\mathrm{I}_{2}, 8 \mathrm{~mol} \%$ & $\mathrm{CH}_{2} \mathrm{Cl}_{2}, \mathrm{rt}$ & 72 & $7: 3$ & 97 & $11 \mathrm{c}$ \\
4 & $\mathbf{1}$ & $\mathrm{InBr}_{3}, 5 \mathrm{~mol} \%$ & $\mathrm{CH}_{2} \mathrm{Cl}_{2}, \mathrm{rt}$ & 90 & $6: 4$ & 89 & $11 \mathrm{~d}$ \\
5 & $\mathbf{3}$ & $\mathrm{InBr}_{3}, 5 \mathrm{~mol} \%$ & $\mathrm{CH}_{2} \mathrm{Cl}_{2}, \mathrm{rt}$ & 87 & $7: 3$ & 97 & $11 \mathrm{e}$ \\
6 & $\mathbf{1}$ & $\mathrm{Bi}(\mathrm{OTf})_{3}, 2 \mathrm{~mol} \%$ & $\mathrm{CH}_{3} \mathrm{CN}, \mathrm{rt}$ & 92 & $7: 3$ & 89 & $11 \mathrm{f}$ \\
\hline
\end{tabular}

An eco-friendly and rapid microwave-assisted method, using 6 equiv. of TMSCN and 20 mol\% of $\mathrm{InCl}_{3}$ (Scheme 45), was developed by Das et al. ${ }^{10 \mathrm{~b}}$ The reactants were taken in $\mathrm{CH}_{3} \mathrm{CN}$ in an open vessel and irradiated for a few seconds. High yields of glycosyl cyanides $\mathbf{8 9}$ and 98 were obtained from acetyl glycals $\mathbf{1}$ and $\mathbf{1 9}$ respectively. The yields and selectivities were comparable to usual reflux methods.<smiles>CC(=O)OC[C@H]1OC=C[C@H](OC(C)=O)[C@H]1OC(C)=O</smiles>

1<smiles>CC(=O)O[C@H]1C=COC[C@H]1OC(C)=O</smiles>

19

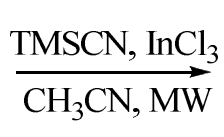<smiles>CC(=O)OC[C@H]1O[C@@H](C#N)C=C[C@H]1OC(C)=O</smiles>

89 $89 \%, \alpha / \beta=6: 4$

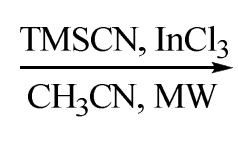
A

$$
\begin{aligned}
& 98 \\
& 72 \%, \alpha / \beta=10: 1
\end{aligned}
$$

\section{Scheme 45}


The inexpensive $\mathrm{ZrCl}_{4}$ was successfully employed in the $C$-Ferrier rearrangement of tri- $O$ acetyl-D-glucal using several nucleophiles. ${ }^{13}$ Herein, only 1.1 equiv. of TMSCN was required to react with glucal 1, in the presence of just $5 \mathrm{~mol} \%$ of $\mathrm{ZrCl}_{4}$, in acetonitrile, in 30 mins. (Scheme 46), affording $75 \%$ of 10:1 mixture of $\alpha$ - and $\beta$-glycosyl cyanides 89.

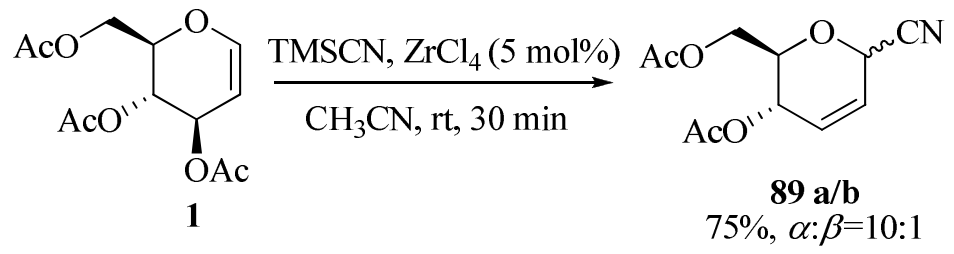

\section{Scheme 46}

In a bid to enhance the catalytic activity and also lower the catalytic loading of $\mathrm{InCl}_{3}$ in $\mathrm{C}$ Ferrier reactions, TMSCl was evaluated for its synergistic effect, ${ }^{10 \mathrm{c}}$ (vide supra). Thus, glucal 1 reacted with 1.5 equiv. of TMSCN in 1 hour in dichloromethane over molecular sieves, to give 90\% of 11:5 mixture of $\alpha$ - and $\beta$-glycosyl cyanides 89 (Scheme 47). Galactal 3 and rhamnal 11 also underwent reaction in good yields of $\mathbf{9 7}$ and 99 respectively. The catalytic system was also observed to be effective in solvent-free conditions.<smiles>CC(=O)OC[C@H]1OC=C[C@@H](OC(C)=O)[C@@H]1OC(C)=O</smiles>

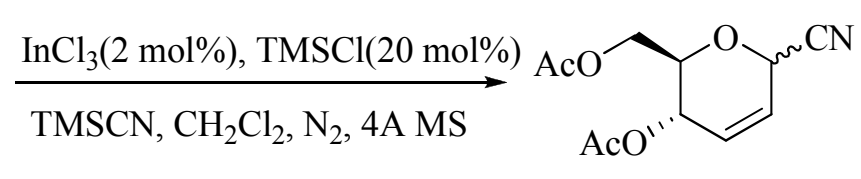

1

89<smiles>CC(=O)OC[C@H]1OC=C[C@@H](OC(C)=O)[C@H]1OC(C)=O</smiles>

3

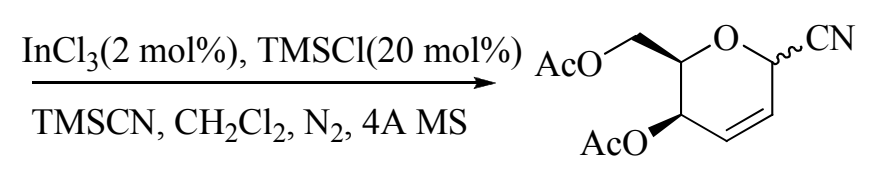

3<smiles>CC(=O)O[C@H]1C=CO[C@@H](C)[C@@H]1OC(C)=O</smiles>

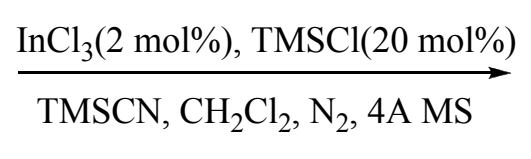

11

\section{Scheme 47}

The proposed reaction mechanism for the regeneration of $\mathrm{InCl}_{3}$ by $\mathrm{TMSCl}$ is illustrated in Figure 4. 


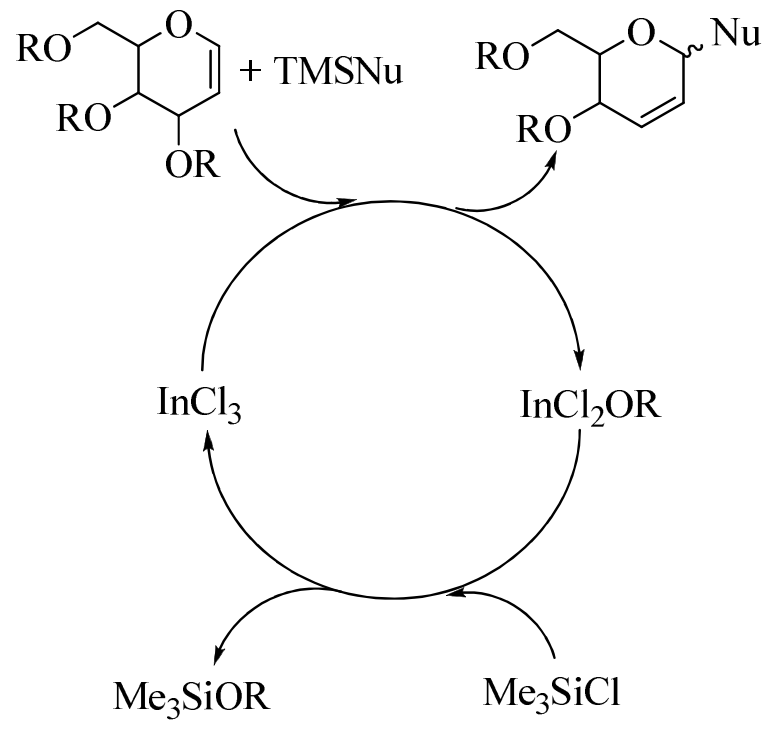

Figure 4. Catalytic cycle and regeneration of $\mathrm{InCl}_{3}$ from TMSCl.

Glucal 1 and galactal 3 also underwent Ferrier rearrangement with TMSCN in the presence of $\mathrm{HClO}_{4}-\mathrm{SiO}_{2}$ catalyst to form the corresponding cyano products 89 and 97 respectively, although the $\alpha / \beta$ ratio (2:1) was only marginally favoring the $\alpha$-anomer. ${ }^{14}$ Likewise, $\operatorname{Er}(\mathrm{OTf})_{3}$ also catalysed the reaction of glycals with TMSCN affording 95\% of glycosyl cyanides (6:4) in the case of glucal 1 and $76 \%$ of cyanides (7:3) in the case of galactal $\mathbf{3}$ favoring $\alpha$-anomers. ${ }^{16}$

\section{Other Nucleophiles}

\subsection{Silyl ketene acetals}

Csuk et al. ${ }^{42}$ reported reaction of glycals with trimethylsilyl ketene acetals under the influence of TMSOTf. Glucal 1 reacted with ketene acetal 100 and afforded a 1:4 mixture of 101a and 101b in a combined yield of $68 \%$ (Scheme 48). Interestingly the same reaction with ketene acetal 102 gave exclusively product $\mathbf{1 0 3}$ but surprisingly in a low yield of only $25 \%$. Moreover, benzoylated glucal 104 gave better yields of $\mathbf{1 0 5}$ on reacting with 100, but 2,3,4,6-tetra- $O$-benzoyl-1,5anhydro-D-arabino-hex-1-enitol 106 gave no reaction at all. Since silyl ketene acetals can be regarded as synthetic equivalents of $\alpha$-trimethylsilyl substituted esters, the expected reaction of glucal 1 with 107 gave a mixture of $\beta$-(57\%) and $\alpha$-(24\%) products 108, while the galactal 3 gave exclusively the product of $\beta$-configuration $\mathbf{1 0 9}$ (Scheme 49). 


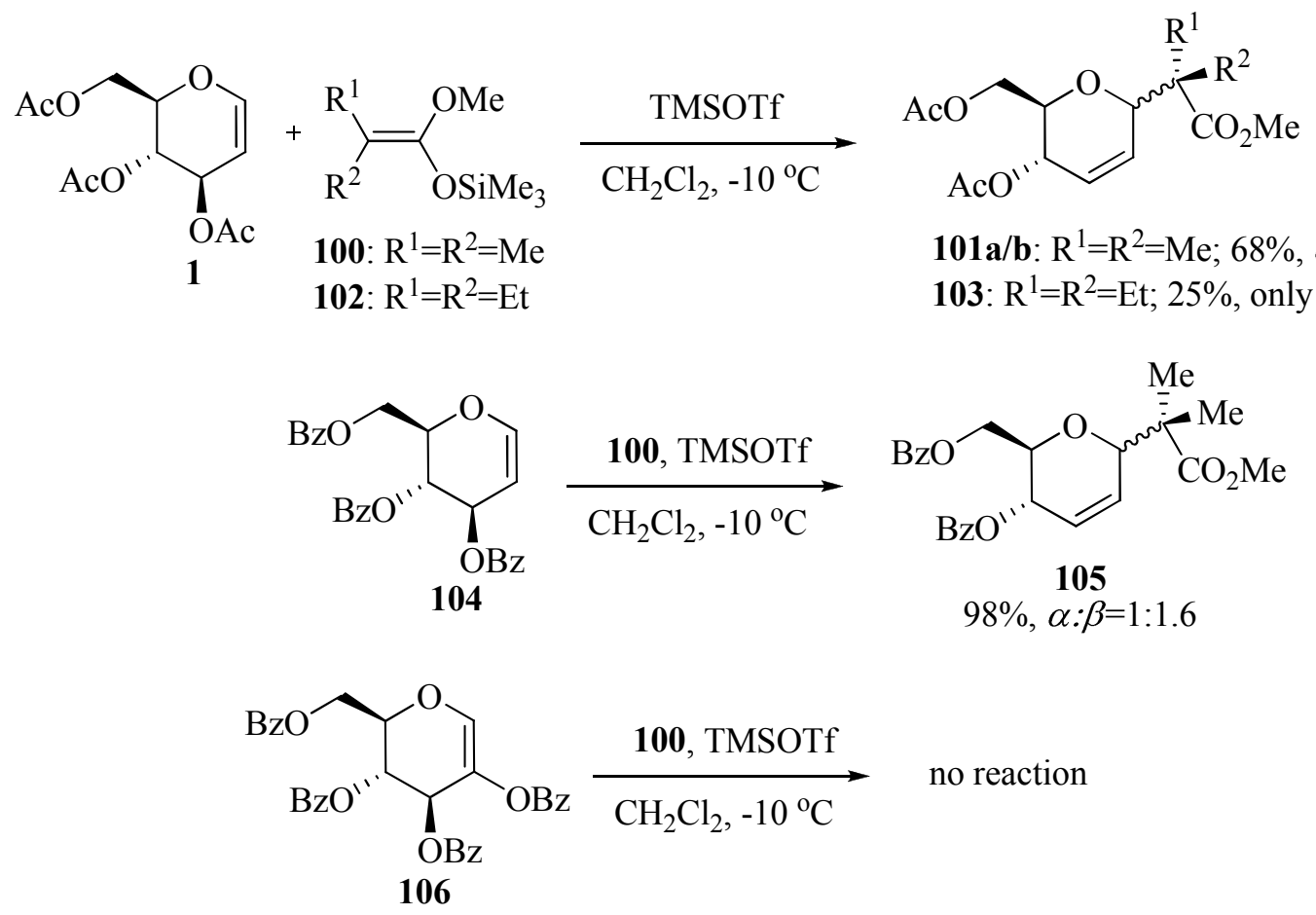

\section{Scheme 48}

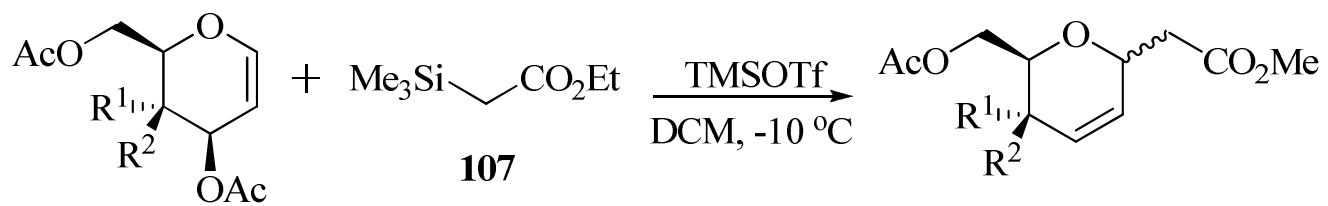

1: $\mathrm{R}^{1}=\mathrm{OAc}, \mathrm{R}^{2}=\mathrm{H}$

3: $\mathrm{R}^{1}=\mathrm{H}, \mathrm{R}^{2}=\mathrm{OAc}$
108: $\mathrm{R}^{1}=\mathrm{OAc}, \mathrm{R}^{2}=\mathrm{H}(81 \%) \alpha / \beta=24: 57$

109: $\mathrm{R}^{1}=\mathrm{H}, \mathrm{R}^{2}=$ OAc only $\beta$

\section{Scheme 49}

Recently, a silylated difluoro-ketene acetal $\mathbf{1 1 0}$ was reported to react with glucal 1,43a yielding $72 \%$ of a $6: 4$ mixture of $\alpha$ - and $\beta$-substituted products 111a and 111b (Scheme 50), and the product was applied to the synthesis of $\alpha-\mathrm{CF}_{2}$-mannosides and fluorinated analogs of pseudoglycopeptides, ${ }^{43}$ and more recently, 2-deoxy-2-aminoglycosides and $\mathrm{CF}_{2}$-aminopyranosides. $^{43 \mathrm{~b}}$

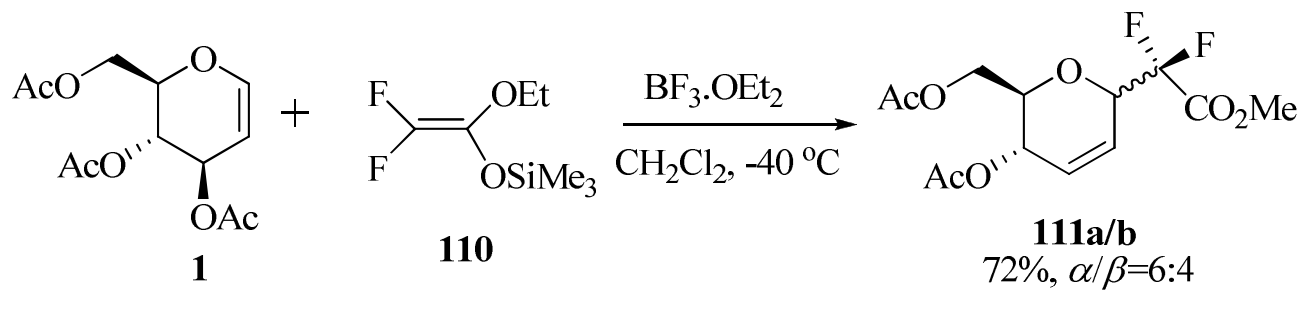

\section{Scheme 50}


Marcaurelle et al. $^{44}$ investigated the reaction of glucal 1 with ketene acetal 112 under various conditions, and found the reaction to be best carried out in the presence of TMSOTf in dichloromethane, yielding $73 \%$ of a 1:1.5 mixture of 108, favouring the $\beta$-anomer (Scheme 51). However on changing the solvent to $\mathrm{CH}_{3} \mathrm{CN}$, the ratio of isomers reversed $(\alpha \cdot \beta=1.5: 1)$ but the yield of $\mathbf{1 0 8}$ lowered to $65 \%$. See also ref. 23 .

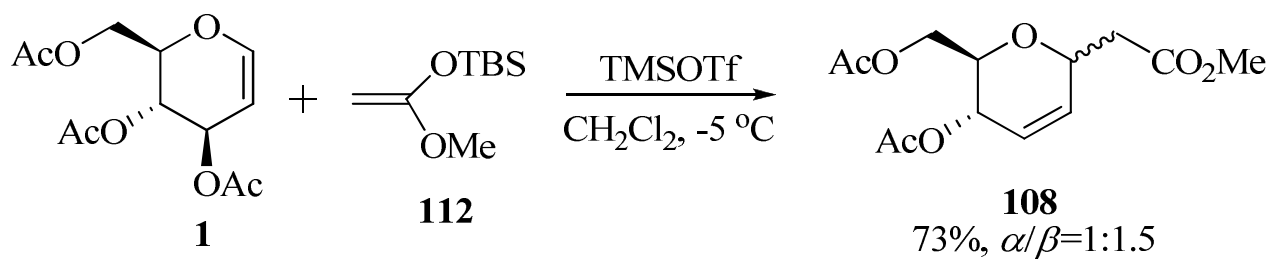

\section{Scheme 51}

\subsection{Aromatic nucleophiles}

Synthetic routes towards $C$-aryl glycosides have gained considerable importance over the past few years since they are part of many biologically active molecules. Hence, the task of coupling the aryl moiety into glycosides is now a challenge in organic synthesis. As early as 1987, Isobe and co-workers carried out glycosidation with furan using glucal $\mathbf{1}$ in the presence of $\mathrm{BF}_{3} \cdot \mathrm{Et}_{2} \mathrm{O}{ }^{4}$ and obtained a 1:1 mixture of 1- and 3-substituted products 113 and 114 respectively (Scheme 52).
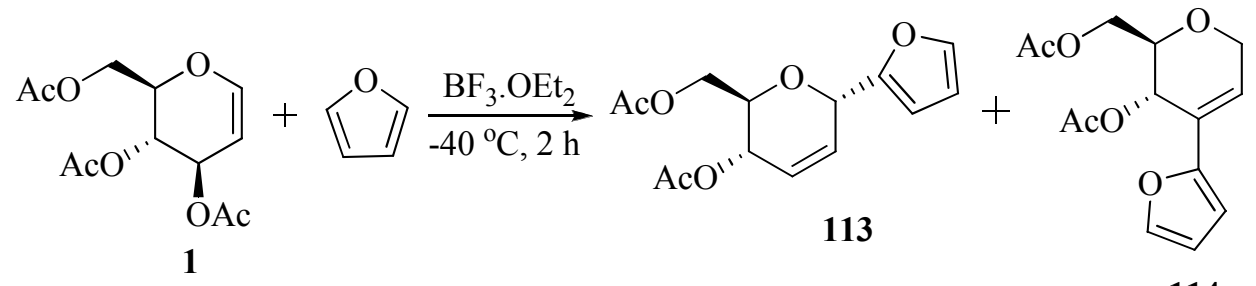

114

\section{Scheme 52}

In the $\mathrm{ZrCl}_{4}$-catalysed Ferrier rearrangement, which was mentioned earlier, ${ }^{13}$ the reaction was also carried out with aromatic nucleophiles such as furan, pyrrole and thiophene, in good yields (Scheme 53) of the corresponding products 113, 115a and $\mathbf{1 1 5} \mathbf{b}$ respectively.

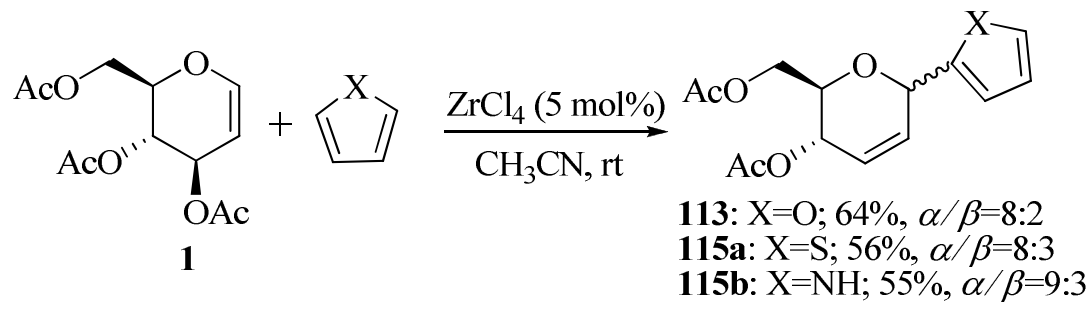

\section{Scheme 53}




\subsection{Electron-rich nucleophiles}

The 1,3-dione 116 and $\beta$-ketoester 118 have been employed in the preparation of corresponding $C$-glycosides 117 and 118 from 1 using $\mathrm{HClO}_{4} \cdot \mathrm{SiO}_{2}$ (Scheme 54). ${ }^{14}$

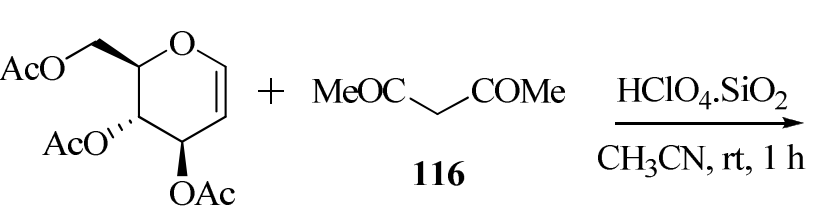

1

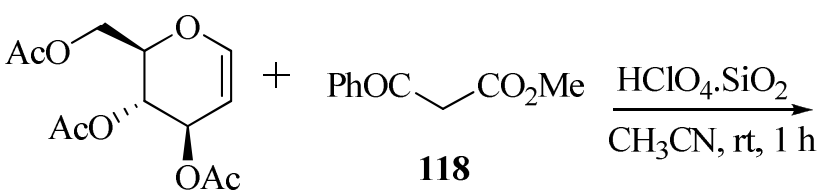

1<smiles>CC(=O)OC[C@H]1O[C@@H](C(C(C)=O)C(C)=O)C=C[C@H]1OC(C)C</smiles>

117

$75 \%, \alpha / \beta=1.5: 1$<smiles>CC(=O)OC[C@H]1O[C@@H](C(C(C)=O)C(=O)c2ccccc2)C=C[C@@H]1C(C)(C)C</smiles>

\section{Scheme 54}

Ethyl acetoacetate (120) has also been utilised in the Ferrier rearrangement on $\mathbf{1}$ using only $0.5 \mathrm{~mol} \%$ of $\mathrm{AuCl}_{3}$, giving $80 \%$ of the product 121 in just 15 minutes (Scheme 55). ${ }^{18}$<smiles>CCOC(=O)CC(C)=O</smiles>

1

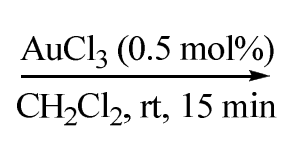

$\overrightarrow{\mathrm{CH}_{2} \mathrm{Cl}_{2}, \mathrm{rt}, 15 \mathrm{~min}}$<smiles>CCOC[C@H]1O[C@@H](C(C(C)=O)C(=O)OCC)C=C[C@H]1OC(C)=O</smiles>

\section{Scheme 55}

\subsection{Olefins}

Peracetylated glycals underwent Ferrier rearrangement with olefins in the presence of Lewis acids such as $\mathrm{SnBr}_{4}$ and $\mathrm{BF}_{3} \cdot \mathrm{Et}_{2} \mathrm{O}$ with complete regioselectivity and high diastereoselectivity, with the $\alpha$-anomer being the major product. ${ }^{28}$ Thus, glucal 1 reacted with olefin 122 to give exclusively $\alpha$-anomer the C-glycosylated 123 in $94 \%$ in the presence of $\mathrm{SnBr}_{4}$ (Scheme 56). In the same way, glucal 59 gave $70 \%$ of only $\alpha$-anomer 124. In the case of methylenecyclobutane 125 and open-chain olefins such as 127, some halogeno derivatives 126 and 128 were obtained when the reaction was carried out in the presence of $\mathrm{EtAlCl}_{2}$. 
<smiles>C=C1CCCCC1</smiles><smiles>C=C1CCCCC1OC(=O)OC1=CO[C@H](COC(C)=O)[C@@H](OC(C)=O)[C@H]1OC(C)=O</smiles><smiles>C=C1CCC1</smiles>

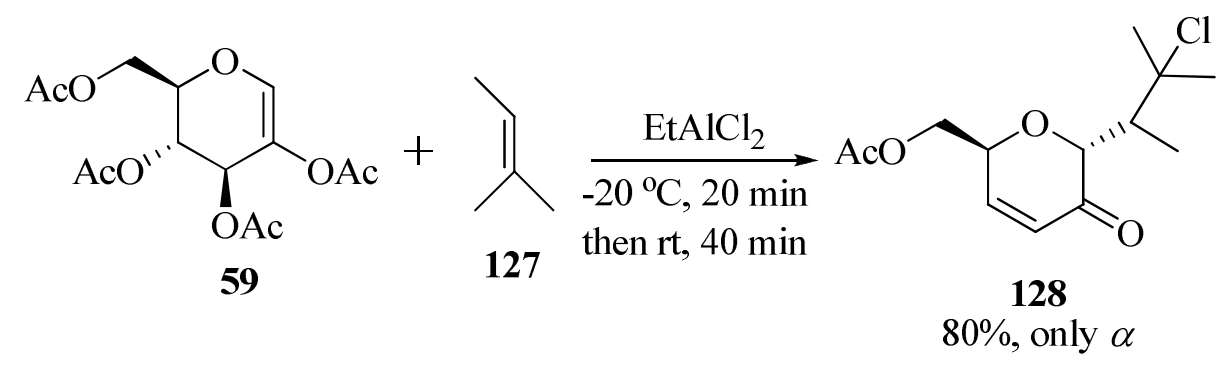

\section{Scheme 56}

More recently, Osborn et al. ${ }^{46}$ prepared the olefin 129 to carry out a similar Ferrier reaction on glycals using $\mathrm{BF}_{3} \cdot \mathrm{Et}_{2} \mathrm{O}$ or $\mathrm{I}_{2}$ as a promoter (Scheme 57), leading to the 1-deoxy-C-linked disaccharide 130. The reaction was optimised with 2:1 ratio of glycal and olefin. Anomeric methoxide undergoes cleavage which also reacts with glycal, hence 2 equiv of glucal is required. The oxonium ion formed by cleavage of the acetal at the anomeric carbon of $\mathbf{1 2 9}$ is reduced by the transfer of hydride from the benzylidene acetal, leading to the subsequent removal of the benzylidene group. Reaction of glucal 1 with olefin 131 under the same conditions led to disaccharide 132 in $51 \%$ yield. Likewise, some other glucal and galactal derivatives also underwent analogous reactions. 
<smiles>CC(=O)OC[C@H]1OC=C[C@H](OC(C)=O)[C@H]1OC(C)=O</smiles>

1<smiles>CC(=O)OC[C@H]1OC=C[CH+][C@H]1OC(C)=O</smiles>

1

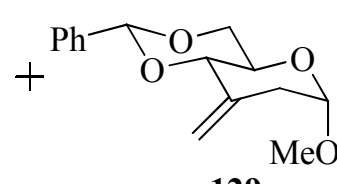

129<smiles>c1ccc(C2OCCC3COC2CO3)cc1</smiles>

131

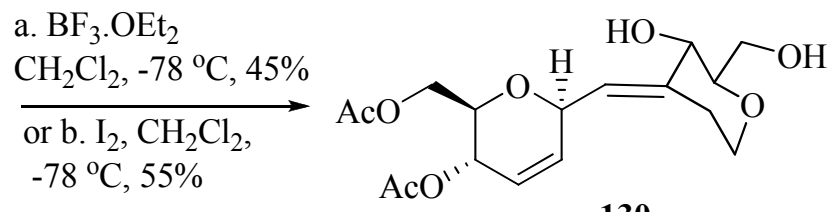

130<smiles>CC(=O)OC[C@H]1O[C@@H](CC2=CCOC(CO)C2O)C=C[C@H]1C(C)=O</smiles>

132

\section{Scheme 57}

\subsection{Isocyanides}

Yadav et al. ${ }^{47}$ reported Ferrier rearrangements with isocyanides as nucleophiles using a catalytic amount of $\mathrm{FeCl}_{3}$ at room temperature. Under these mild reaction conditions, $C$-glycosyl amides 133 were obtained in good yields with high selectivity (Scheme 58). Several differently protected glucals reacted efficiently with the isonitriles in the presence of only $10 \mathrm{~mol} \% \mathrm{FeCl}_{3}$ at room temperature.<smiles></smiles>

1

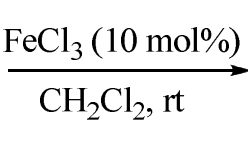

\section{Scheme 58}

\subsection{Allenyl silanes}

Very recently, enantio-enriched allenyl silane $\mathbf{1 3 4}$ has been used for $C$-glycosidation under the influence of TMSOTf. ${ }^{48}$ The products 135 and 136 displayed very good diastereoselectivity, favouring the $\alpha$-isomer (Scheme 59). Additions on glucal were considerably higher yielding than the analogous galactal additions. Even achiral allenyl silane 137 was used for this reaction, giving similar results forming 138. Moreover, the 2,3-dihydrofuran 139, prepared from D-ribose, underwent reaction with both enantiomers of 134, affording trans dihydrofuran products 140a and 140b, albeit in lower yields (Scheme 60). Again, addition of 137 on dihydrofuran 139 gave moderate to high yield of 2,5-trans-dihydrofuran 141. 

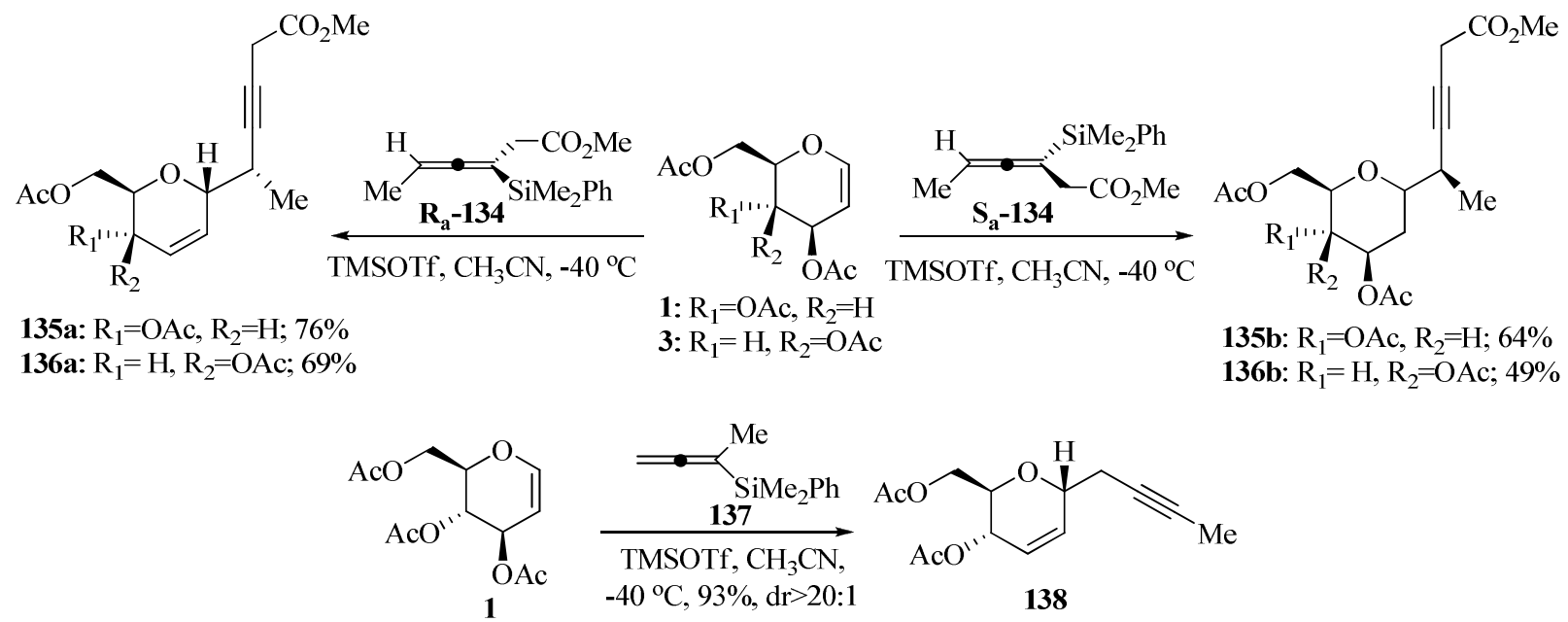

Scheme 59
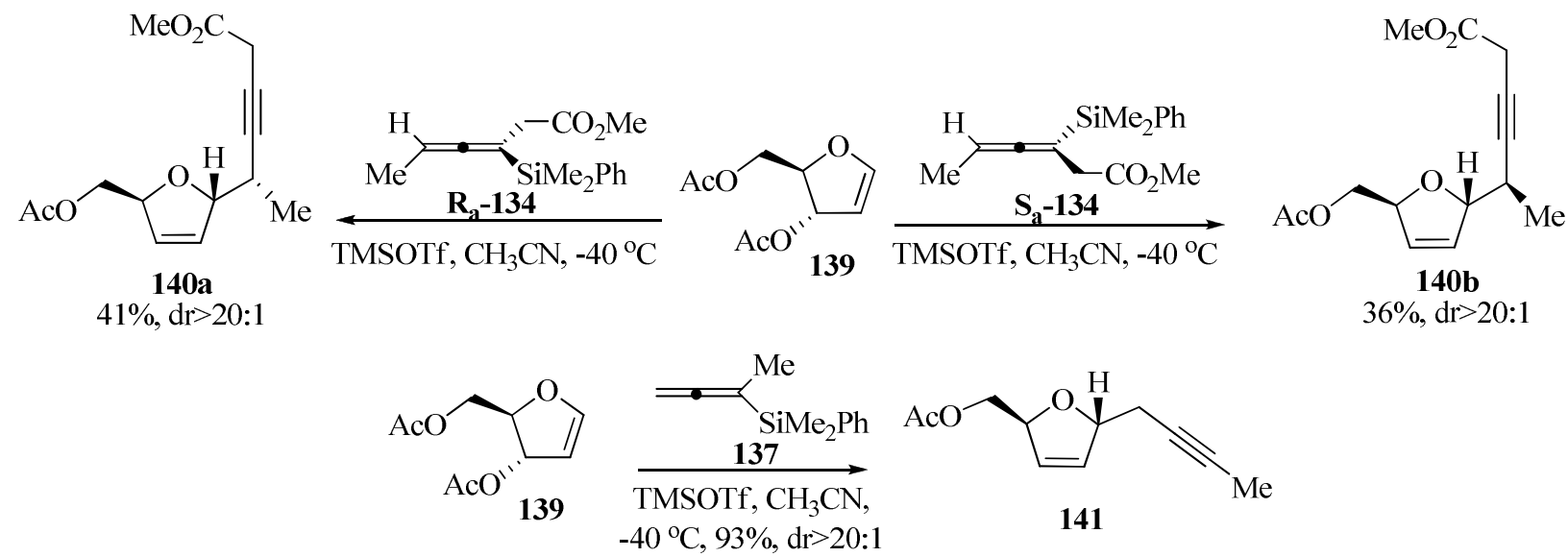

\section{Scheme 60}

\subsection{Organoboron compounds}

Potassium alkynyltrifluoroborates have been successfully employed in the $C$-glycosidation of Dglucal 1 using $\mathrm{BF}_{3} \cdot \mathrm{OEt}_{2}{ }^{48}$ These salts are stable in air and moisture, and more nucleophilic as compared to organoboron compounds. The reaction was performed under 2 sets of conditionsusing 4 equiv. of $\mathrm{BF}_{3} . \mathrm{OEt}_{2}$ at $-45^{\circ} \mathrm{C}$ in acetonitrile gave products 142 in 20 min or using 2 equiv. of $\mathrm{BF}_{3} . \mathrm{OEt}_{2}$ at $0{ }^{\circ} \mathrm{C}$ allowed the reaction to complete within 10 minutes (Scheme 61). Both methods gave good yields with high $\alpha$-selectivity, with the former method giving higher selectivity in some cases.
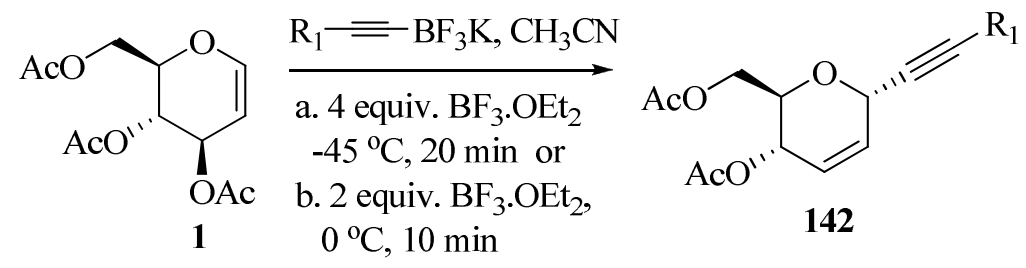

\section{Scheme 61}


$\mathrm{BF}_{3} . \mathrm{Et}_{2} \mathrm{O}$ is believed to convert the trifluoroborate into the organoboron difluoride $\mathbf{1 4 3}$, which is able to activate the acetate of the glucal $\mathbf{1}$, generating a $\left[\mathrm{R}-\mathrm{B}(\mathrm{OAc}) \mathrm{F}_{2}\right]^{-}$kind of nucleophilic species, which attacks the $\mathrm{C}-1$ oxonium ion, ultimately giving rise to 142 (Figure 5).

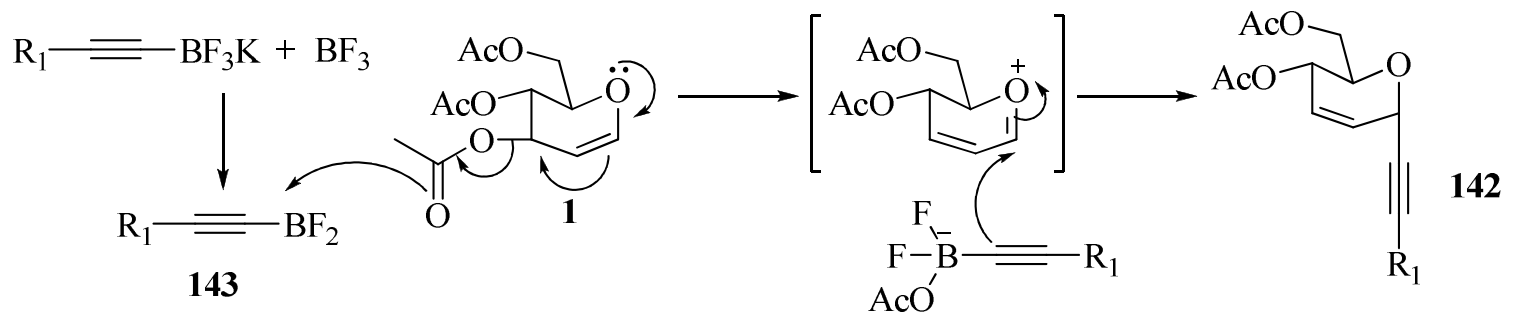

Figure 5. Mechanistic representation of C-Ferrier rearrangment by potassium alkynyltrifluoroborates.

\section{Conclusions}

From the foregoing discussion, it is clear that a wide range of carbon nucleophiles and a great number of catalysts have been studied to bring about the carbon-Ferrier rearrangement leading to C-glycosides. Although a good amount of progress in terms of improvements in yield, selectivity etc. has been reported, there is still in many reactions room for improvement. It is expected that this review will give sufficient impetus to readers to embark on the development of new catalysts and introduction of new nucleophiles in the carbon-Ferrier rearrangement.

\section{Acknowledgements}

We thank the Department of Science and Technology, New Delhi and Council of Scientific and Industrial Research (CSIR), New Delhi for financial support. AAA and RL thank the CSIR, New Delhi for Senior Research Fellowships.

\section{References}

1. (a) Ferrier, R. J. J. Chem Soc. (C) 1964, 5443-5449.

(b) Ferrier, R. J.; Middleton, S. Chem Rev. 1993, 93, 2779-2831. http://dx.doi.org/10.1021/cr00024a008

(c) Ferrier R. J.; Hoberg J. O. Adv. Carbohydr. Chem. Biochem. 2003, 58, 55-119. http://dx.doi.org/10.1016/S0065-2318(03)58003-9

(d) Ferrier R. J. Top. Curr. Chem. 2001, 215, 153-175. 
(e) Liu, Q.; Zhang, G. Chinese J. Org. Chem. 2009, 29, 1890-1898.

(f) Agarwal, A.; Rani, S.; Vankar, Y. D. J. Org. Chem., 2004, 70, 6137-6140. http://dx.doi.org/10.1021/jo049415j, PMid:15373503

(g) Babu, J. L.; Khare, A.; Vankar, Y. D. Molecules 2005, 10, 884-892. http://dx.doi.org/10.3390/10080884

(h) Ding, F.; William, R.; Gorityala, B. K.; Ma, J.; Wang, S.; Liu, X.-W. Tetrahedron Lett. 2010, 51, 3146-3148. http://dx.doi.org/10.1016/j.tetlet.2010.04.045

(i) Reddy, B. V. S.; Divyavani, C.; Yadav, J. S. Synthesis 2010, 1617-1620. http://dx.doi.org/10.1055/s-0029-1218722

2. Danishefsky, S.; Kerwin, J. F. J. Org. Chem. 1982, 47, 3803-3805. http://dx.doi.org/10.1021/jo00140a053

3. Nicolaou, K. C.; Hwang, C.-K.; Duggan, M. E. J. Chem. Soc., Chem. Commun. 1986, 925926.

4. Ichikawa, Y.; Isobe, M.; Konobe, M.; Goto, T. Carbohdyr. Res. 1987, 171, 193-199. http://dx.doi.org/10.1016/S0008-6215(00)90886-3

5. Kozikowski, A. P.; Park, P. J. Org. Chem. 1990, 55, 4668-4682. http://dx.doi.org/10.1021/jo00302a036

6. Toshima, M.; Ishizuka, T.; Matsuo, G.; Nakata, M. Chemistry Lett. 1993, 2013-2016. http://dx.doi.org/10.1246/cl.1993.2013

7. Toshima, K.; Miyamoto, N.; Matsuo, G.; Nakata, M.; Matsumara, S. Chem. Commun. 1996, 1379-1380. http://dx.doi.org/10.1039/cc9960001379

8. Toshima, K.; N.; Matsuo, G.; Ishizuka, T.; Ushiki, Y.; Nakata, M.; Matsumara, S. J. Org. Chem. 1998, 63, 2307-2313. http://dx.doi.org/10.1021/jo972146v

9. Hosakawa, S.; Kirschbaum, B.; Isobe, M. Tetrahedron Lett. 1998, 39, 1917-1920. http://dx.doi.org/10.1016/S0040-4039(98)00047-1

10. (a) Ghosh, R.; De, D.; Shown, B.; Maiti, S. B. Carbohydr. Res. 1999, 321, 1-3.

(b) Das, S. K.; Reddy, K. A.; Abbineni, C.; Roy, J.; Rao, K. V. L. N.; Sachwani, R. H.; Iqbal, J. Tetrahedron Lett. 2003, 44, 4507-4509. http://dx.doi.org/10.1016/S0040- 4039(03)01012-8

11. (a) Yadav, J. S.; Reddy, B. V. S.; Chand, P. K. Tetrahedron Lett. 2001, 42, 4057-4059. http://dx.doi.org/10.1016/S0040-4039(01)00629-3

(b) Yadav, J. S.; Reddy, B. V. S.; Venkateshwar Rao, C.; Chand, P. K.; Prasad, A. R. Synlett 2001, 28, 1638-1640. http://dx.doi.org/10.1055/s-2002-20968

(c) Yadav, J. S.; Reddy, B. V. S. Synthesis 2002, 4, 511-514. http://dx.doi.org/10.1055/s-2002-20968

(d) Yadav, J. S.; Reddy, B. V. S.; Reddy, K. S.; Sunitha, C. V. Synthesis 2004, 15, 25232526. http://dx.doi.org/10.1055/s-2004-831187 
(e) Yadav, J. S.; Satyanarayana, M.; Balanarsaiah, E.; Raghavendra, S. Tetrahedron Lett. 2006, 47, 6095-6098. http://dx.doi.org/10.1016/j.tetlet.2006.06.084

(f) Yadav, J. S.; Reddy, B. V. S.; Chandraiah, L.; Reddy, K. S. Carbohydr. Res. 2001, 332, 221-224. http://dx.doi.org/10.1016/S0008-6215(01)00087-8.

12. (a) Takhi, M.; Rahman, A. A.-H. A.; Schmidt, R. R. Tetrahedron Lett. 2001, 42, 4053-4056.

(b) Sasaki, M.; Tsubone, K.; Shoji, M.; Oikawa, M.; Shimamoto, K.; Sakai, R. Bioorg. Med. Chem. Lett. 2006, 16, 5784-5787. http://dx.doi.org/10.1016/j.bmcl.2006.08.082, PMid:16949819.

(c) Anjaiah, S.; Chandrasekhar, S.; Grée, R. J. Mol. Cat. A: Chemical 2004, 214, 133-136. http://dx.doi.org/10.1016/j.molcata.2003.10.063.

13. Swamy, N. R.; Srinivasulu, M.; Reddy, T. S.; Goud, T. V.; Venkateswarlu, Y. J. Carbohydr. Chem. 2004, 23, 435-441. http://dx.doi.org/10.1081/CAR-200040119.

14. Tiwari, P.; Agnihotri, G.; Misra, A. K. Carbohdyr. Res. 2005, 340, 749-752. http://dx.doi.org/10.1016/j.carres.2004.12.022, PMid:15721348.

15. (a) Lin, H.; Du, W.; Chang, C.; Lin, C. Tetrahedron Lett. 2005, 46, 5071-5076.

(b) Gallagher, B. M.; Zhao, H.; Pesant, M.; Fang, F. G. Tetrahedron Lett. 2005, 46, 923-926. http://dx.doi.org/10.1016/j.tetlet.2004.12.056.

16. Procopio, A.; Dalpozzo, R.; De Nino, A.; Nardi, M.; Russo, B.; Tagarelli, A. Synthesis 2006, 2, 332-338. http://dx.doi.org/10.1055/s-2005-918504

17. Fernandes, A.; Dell'Olmo, M.; Tatinouët, A.; Imberty, A.; Philouze, C.; Rollin, P. Tetrahedron Lett. 2008, 49, 3484-3488. http://dx.doi.org/10.1016/j.tetlet.2008.03.093.

18. Balamurugan, R.; Koppolu, S. R. Tetrahedron 2009, 65, 8139-8142. http://dx.doi.org/10.1016/j.tet.2009.07.087.

19. Levecque, P.; Gammon, D. W.; Jacobs, P.; De Vos, D.; Sels, B. Green Chem. 2010, 12, 828-835. http://dx.doi.org/10.1039/b921051b.

20. Danishefsky, S. J.; DeNinno, S.; Lartey, P. J. Am. Chem. Soc. 1987, 109, 2082-2089. http://dx.doi.org/10.1039/b921051b.

21. Panek, J. S.; Schaus, J. V. Tetrahedron 1997, 53, 10971-10982. http://dx.doi.org/10.1021/ja00241a028.

22. Dawe, R. D.; Fraser-Reid, B. J. Chem. Soc., Chem. Commun. 1981, 1180-1181. http://dx.doi.org/10.1016/S0040-4020(97)00358-X

23. Pearson, W. H.; Schkeryantz, J. M. J. Org. Chem. 1992, 57, 2986-2987. http://dx.doi.org/10.1021/jo00037a004

24. Orsini, F.; Pelizzoni, F. Carbohydr. Res. 1993, 243, 183-189. 
http://dx.doi.org/10.1021/jo00037a004

25. (a) Thorn, S. N.; Gallagher, T. Synlett, 1996, 185-186.

http://dx.doi.org/10.1055/s-1996-5346

(b) Cook, M. J.; Fletcher, M. J. E.; Gray, D.; Lovell, P. J.; Gallagher, T. Tetrahedron 2004, 60, 5085-5092.

http://dx.doi.org/10.1016/j.tet.2004.04.004

26. Dorgan, B. J.; Jackson, R. F. W. Synlett 1996, 1, 859-861.

http://dx.doi.org/10.1055/s-1996-5599

27. Cossy, J.; Rakotoarisoa, H. Synlett 2000, 5, 734-736.

28. Ramnauth, J.; Poulin, O.; Rakhit, S.; Maddaford, S. P. Org. Lett. 2001, 3, 2013-2015. http://dx.doi.org/10.1021/ol010070q

29. Steinhuebel, D. P.; Fleming, J. J.; Du Bois, J. Org. Lett. 2002, 4, 293-295. http://dx.doi.org/10.1021/o1010273e

30. Xue, S.; He, L.; Han, K.-Z.; Zheng, X.-Q.; Guo, Q.-X. Carbohydr. Res. 2005, 340, 303-307. http://dx.doi.org/10.1016/j.carres.2004.11.012

31. Ayed, C.; Palmier, S.; Lubin-Germain, N.; Uziel, J.; Augé, J. Carbohydr. Res. 2010, 345, 2566-2570. http://dx.doi.org/10.1016/j.carres.2010.07.033

32. Lubin-Germain, N.; Hallonet, A.; Huguenot, F.; Palmeir, S.; Uziel, J.; Augé, J. Org. Lett. 2007, 9, 3679-3682. http://dx.doi.org/10.1021/ol701480x

33. (a) Tsukiyama, T.; Isobe, M. Tetrahedron Lett. 1992, 33, 7911-7914. http://dx.doi.org/10.1016/S0040-4039(00)74776-9

(b) Isobe, M.; Nishizawa, R.; Hosokawa, S.; Nishikawa, T. Chem. Commun. 1998, 26652676.

http://dx.doi.org/10.1039/a804940h

34. Tsukiyama, T.; Peters, S. C.; Isobe, M. Synlett 1993, 413-414. http://dx.doi.org/10.1055/s-1993-22476

35. (a) Zhu, Y. H.; Vogel. P. Synlett 2001, 2, 82-86.

(b) Huang, G.; Isobe, M. Tetrahedron 2001, 57, 10241-10246. http://dx.doi.org/10.1016/S0040-4020(01)01066-3

36. Yadav, J. S.; Reddy, B. V. S.; Raju, A. K.; Rao, C. V. Tetrahedron Lett. 2002, 43, 54375440.

http://dx.doi.org/10.1016/S0040-4039(02)01081-X

37. Saeeng, R.; Sirion, U.; Sahakitpichan, P.; Isobe, M. Tetrahedron Lett. 2003, 44, 6211-6215. http://dx.doi.org/10.1016/S0040-4039(03)01540-5

38. Isobe, M.; Phoosaha, W.; Saeeng, R.; Kira, K.; Yenjai, C. Org. Lett. 2003, 5, 4883-4884. http://dx.doi.org/10.1021/o1035957w

39. Saeeng, R.; Isobe, M. Org. Lett. 2005, 7, 1585-1588. http://dx.doi.org/10.1021/o1050265o 
40. De Las Heras, F. G.; Felix, A. S.; F-Resa, P. Tetrahedron 1983, 39, 1617-1620. http://dx.doi.org/10.1016/S0040-4020(01)88571-9

41. Hayashi, M. Kawabata, H.; Inoue, K. Carbohydr. Res. 2000, 35, 68-71. http://dx.doi.org/10.1016/S0008-6215(99)00302-X

42. Csuk, R.; Schaade, M.; Krieger, C. Tetrahedron 1996, 18, 6397-6408. http://dx.doi.org/10.1016/0040-4020(96)00275-X

43. (a) Poulain, F.; Serre, A. -L.; Lalot, J.; Leclerc, E.; Quirion, J.-C. J. Org. Chem. 2008, 73, 2435-2438. http://dx.doi.org/10.1021/jo702466h

(b) Poulain, F.; Leclerc, E.; Quirion, J.-C. Tetrahedron Lett. 2009, 50, 1803-1805. http://dx.doi.org/10.1016/j.tetlet.2009.01.155

44. Gerard, B.; Marie, J.-C.; Pandya, B. A.; Lee IV, M. D.; Liu, H.; Maracaurelle, L. A. J. Org. Chem. 2011, 76, 1898-1901. http://dx.doi.org/10.1021/jo1022926

45. Herscovici, J.; Muleka, K.; Boumaiza, L.; Antonakis, K. J. Chem. Soc. Perkin Trans. 1, 1990, 1995-2000.

46. Gemmell, N.; Meo, P.; Osborn, H. M. I. Org. Lett. 2003, 5, 1649-1652. http://dx.doi.org/10.1021/ol030023t

47. Yadav, J. S.; Reddy, B. V. S.; Chary, D. N.; Madavi, C.; Kunwar, A. C. Tetrahedron Lett. 2009, 50, 81-84. http://dx.doi.org/10.1016/j.tetlet.2008.10.090

48. Brawn, R. A.; Panek, J. S. Org. Lett. 2010, 12, 4624-4627. http://dx.doi.org/10.1021/ol1019629

49. Vieira, A. S.; Fiorante, P. F.; Hough, T. L. S.; Ferreira, F. P.; Ludtke, D. S.; Stefani, H. A. Org. Lett. 2008, 10, 5215-5218. http://dx.doi.org/10.1021/ol8022177

\section{Authors' Biographies}

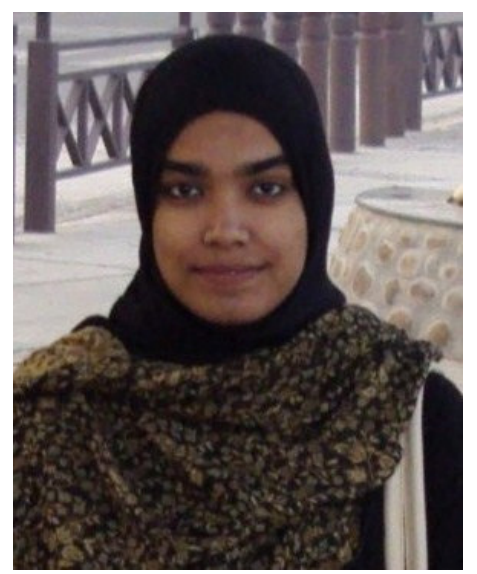


Alafia Ali Ansari has received her B.Sc and M.Sc. degrees in 2005 and 2007, from Aligarh Muslim University, India. She is currently pursuing her Ph.D. under the supervision of Prof. Y. D. Vankar, Department of Chemistry, IIT Kanpur, India since 2008. Her research work includes the synthesis of glycosidase inhibitors and development of newer synthetic methodologies in carbohydrate chemistry.

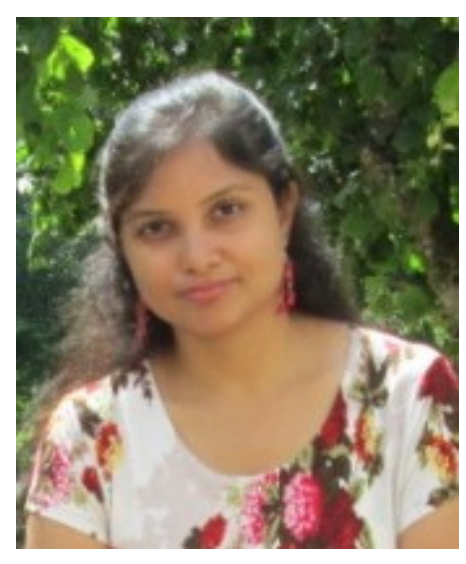

Rima Lahiri obtained her Bachelor's Degree from Presidency College, Kolkata, India in 2005 and joined M.Sc. in IIT Kanpur, India. After completion of her master's programme she joined as a Ph. D. Student under the supervision of Prof. Y. D. Vankar in IIT Kanpur, India in 2007. She has been working in the area of synthetic organic chemistry and her research involves multistep syntheses towards natural and unnatural iminosugars as potential glycosidase inhibitors.

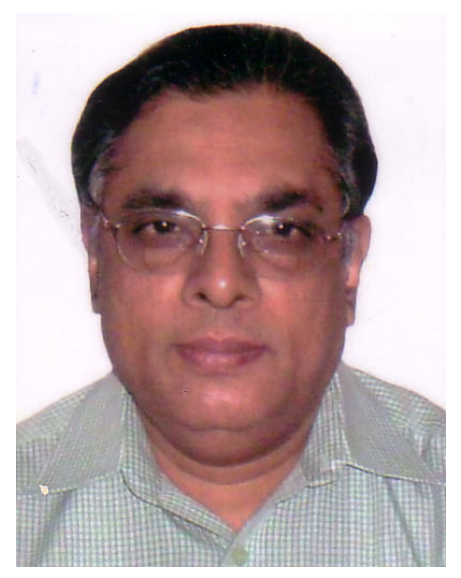

Yashwant D. Vankar was born in 1950 in Varanasi, India. He obtained his M.Sc. (Organic Chemistry) degree from the Banaras Hindu University, Varanasi in 1971. He obtained his Ph.D. degree at the National Chemical Laboratory, Pune, India under the guidance of Professor B. D. Tilak. He then worked as a post-doctoral fellow at King's College, London (with Professor David I. Davies, 1976-1977), at the University of Southern California, Los Angeles (with Nobel 
Laureate Profesor George A. Olah, 1977-1979) and then at Rice University, Houston (with Professor Ernest Wenkert, 1979-1980). After returning to India he joined the chemistry department at the Indian Institute of Technology Kanpur as a Lecturer in 1981, and since 1991 he has been a full professor at the same institute. He spent a year (1990-1991) as an Alexander von Humboldt fellow at the Universität Konstanz, Germany (with Professor Richard R. Schmidt). His major research interests are different aspects of synthetic organic chemistry with special emphasis on carbohydrate chemistry of biological importance and the development of newer methodologies. He is a fellow of the Indian Academy of Sciences, Bangalore and Indian National Science Academy, New Delhi. 